\title{
Internet of Things for Current COVID-19 and Future Pandemics: an Exploratory Study
}

\author{
Mohammad Nasajpour ${ }^{1}$. Seyedamin Pouriyeh ${ }^{1}$ (D) $\cdot$ Reza M. Parizi ${ }^{2}$. \\ Mohsen Dorodchi ${ }^{3}$ - Maria Valero ${ }^{1}$ - Hamid R. Arabnia ${ }^{4}$
}

Received: 26 July 2020 / Revised: 1 October 2020 / Accepted: 7 October 2020 /

Published online: 12 November 2020

(C) Springer Nature Switzerland AG 2020

\begin{abstract}
In recent years, the Internet of Things (IoT) has gained convincing research ground as a new research topic in a wide variety of academic and industrial disciplines, especially in healthcare. The IoT revolution is reshaping modern healthcare systems by incorporating technological, economic, and social prospects. It is evolving healthcare systems from conventional to more personalized healthcare systems through which patients can be diagnosed, treated, and monitored more easily. The current global challenge of the pandemic caused by the novel severe respiratory syndrome coronavirus 2 presents the greatest global public health crisis since the pandemic influenza outbreak of 1918. At the time this paper was written, the number of diagnosed COVID-19 cases around the world had reached more than 31 million. Since the pandemic started, there has been a rapid effort in different research communities to exploit a wide variety of technologies to combat this worldwide threat, and IoT technology is one of the pioneers in this area. In the context of COVID-19, IoT-enabled/linked devices/applications are utilized to lower the possible spread of COVID-19 to others by early diagnosis, monitoring patients, and practicing defined protocols after patient recovery. This paper surveys the role of IoT-based technologies in COVID-19 and reviews the state-of-the-art architectures, platforms, applications, and industrial IoT-based solutions combating COVID-19 in three main phases, including early diagnosis, quarantine time, and after recovery.
\end{abstract}

Keywords Internet of things · Medical IoT · COVID-19 · IoT · Industrial IoT · Healthcare · Pandemic · Coronavirus · Infectious disease

This article belongs to the Topical Collection: Special Collection on COVID-19 Guest Editors: Christopher C. Yang, Julio Cesar Facelli, David Buckeridge, Fei Wang

Seyedamin Pouriyeh spouriye@kennesaw.edu

Extended author information available on the last page of the article. 


\section{Introduction}

The term "Internet of Things" (IoT) was first coined in a presentation by Kevin Ashton about implementing radio-frequency identification (RFID) in the Procter and Gamble company for supply chain management [1]. IoT is an advanced technology that can link all smart objects together within a network with no human interactions [2]. More simply, any object that can be connected to the internet for further monitoring or transferring data can be an IoT device [3].

In recent years, IoT has gained convincing research ground as a new research topic in a wide variety of academic and industrial disciplines, especially in healthcare. The IoT revolution is reshaping modern healthcare systems, incorporating technological, economic, and social prospects. It is evolving healthcare systems from conventional to more personalized healthcare systems through which patients can be diagnosed, treated, and monitored more easily.

IoT is increasingly becoming a vital technology in healthcare systems where it can deliver lower expenses, a better quality of services, and advanced user experiences [4-7]. As a result of its wide capabilities including tracking, identification and authentication, and data collection, the exponential growth of IoT in healthcare is expected to rise from USD 72 billion in 2020 to USD 188 billion in 2025 [2, 8].

The current global challenge of the pandemic caused by the novel severe respiratory syndrome coronavirus 2 presents the greatest global public health crisis since the pandemic influenza outbreak of 1918 [9]. According to the last report of the World Health Organization (WHO), as of September 2020, the number of confirmed COVID-19 cases passed 31 million people with an approximate huge death toll of 960,000 people [10]. This disease has similar symptoms as the flu such as fever, cough, and fatigue, which are essential to recognize for early diagnosis [11]. The incubation period of COVID-19 takes from 1 to 14 days. Surprisingly, a patient without any symptoms can possibly be a transmitter of the COVID-19 virus to others. This is when quarantining such people is necessary [12]. Moreover, the recovery period of this disease varies and depends on the patient's age, underlying conditions, etc., but in general it can take between 6 to 41 days [13]. While this disease has a high potential to be spread easily in comparison with similar diseases within the coronavirus family, there are many ongoing efforts and much research to mitigate the spread of this virus. In this context, IoT technology has been shown to be a safe and efficient way of dealing with the COVID-19 pandemic [14-16].

Our goal in this study is to determine the role of IoT-based technologies in COVID-19 tracking and control and review the state-of-the-art architectures, platforms, applications, and industrial IoT-based solutions combating COVID-19 in three main phases, including early diagnosis, quarantine time, and after recovery.

Early detection and diagnosis can lead to fewer infection and, as a result, better health services for infected patients [17]. Quarantining confirmed or suspected cases and enforcing lockdowns can also decrease the number of COVID-19 infections by separating infected people from others. Tracking COVID-19 patients after recovery will benefit the monitoring of returning symptoms and the potential infectivity of these recovered cases [18]. 
The remainder of the paper is organized as follows. Section 2 covers the importance of IoT during COVID-19. Section 3 highlights IoT technologies along with their categories for the phase of "Early Diagnosis." Similarly, Section 4 and 5 review IoT technologies in "Quarantine Time" and "After Recovery" phases respectively. Finally, we discuss, outline future work, and conclude in Sections 6 and 7 respectively.

\section{Important Role of IoT in COVID-19}

Since early 2020, the world has been struggling with the pandemic caused by the novel severe respiratory syndrome coronavirus 2 by striving to control the unprecedented spread of the virus and develop a vaccine [19]. As most efforts to find a treatment or control the spread of the COVID-19 have not shown acceptable results so far, there is a high demand for global monitoring of patients with symptomatic and asymptomatic COVID-19 infection.

In recent years, IoT technology has received significant attention in the healthcare domain where it plays an important role in different phases of various infectious diseases [20]. In the current pandemic, as the contingency of COVID-19 is high, there is an essential need for patients to be connected with and monitored by their physicians proactively in different phases of COVID-19. In this study, we investigate the role of IoT technology in response to COVID-19 in three main phases including early diagnosis, quarantine time, and after recovery.

During the first phase of COVID-19, which is early diagnosis [21], there is an essential need for faster diagnosis due to the high rate of contagiousness of COVID19 where even an asymptomatic patient can easily spread the virus to others. The sooner the patient is diagnosed, the better the spread of the virus can be controlled, and the patient can receive appropriate treatment. In fact, IoT devices can speed up the detection process by capturing information from patients. This can be implemented by capturing body temperatures using different devices, taking samples from suspicious cases, and so on.

The second phase, called quarantine time [22], is an important period of this disease after the patient has been diagnosed with COVID-19, and he or she should be isolated for the course of treatment. IoT devices in this phase can monitor patients remotely [23] with respect to their treatments and stay at home orders by the authorities. They can also clean areas without human interactions. Examples of these types are the implementation of tracking wearable bands, disinfecting devices, etc.

According to the Centers for Disease Control and Prevention (CDC) [24], most people with mild symptoms can recover while staying at home without getting treatments, but there is no guarantee those people will not be reinfected after recovery. Reinfection might happen with different symptoms of COVID-19 [25]. Concerning these possible reinfections in the after recovery phase, the chances of returning symptoms and potential infectivity can be high [18]. To prevent that happening, social distancing should be implemented by deploying IoT devices, including bands 
and crowd monitoring devices, to track people to ensure the appropriate distance is maintained. In short, IoT technology during the COVID-19 pandemic has proven its usefulness in assisting patients, healthcare providers, and authorities. In this section, we briefly explain the various IoT devices and applications including wearables, drones, robots, IoT buttons, and smartphone applications that are mainly utilized in the forefront of combating COVID-19. Table 1 lists the specifications of these technologies regarding this pandemic.

\subsection{Wearables}

Wearable technologies can be defined as the combination of electronics with anything that is able to be worn [26]. The definition presented by Juniper Research [27] describes them as app-enabled computing technologies that receive and process input while they are either worn or stick to the body such as bands, glasses, and watches. These smart wearables were designed for different purposes in various domains such as healthcare, fitness, lifestyle, and so on [27-29]. Although the privacy of data is still a significant issue for expanding these devices, it is predicted that healthcare providers will spend \$20 billion annually until 2023 on wearable IoT devices to monitor more patients [30]. IoT wearable devices cover a wide range of different smart wearable tools such as Smart Themormeters [31, 32], Smart Helmets [33], Smart Glasses [34], IoT-Q-Band [35], EasyBand [36], and Proximity Trace [37]. Table 2 shows all wearable devices regarding their classification with examples.

\subsection{Drones}

Drones are simply aircraft that are flown without any or very little human operation by remote monitoring [38]. In 1849, during a war between Italy and Austria, the first drone, which was a balloon equipped with bombs, was used [39]. The drone is also known as an unmanned aerial vehicle (UAV) that works with the help of sensors, GPS, and communication services. The implementation of IoT within drones, known as the Internet of Drone Things (IoDT), makes it possible for drones to do a variety of tasks such as searching, monitoring, and delivering [40, 41]. Smart drones can be operated by a smartphone and a controller with a minimum of time and energy, which makes them efficient in different fields such as agriculture, the military, and healthcare. Different types of IoT-based drones, including thermal imaging drone [42], disinfectant drone [43], medical drone [44], surveillance drone [45], announcement drone [46], and multipurpose drone [47] are used in the healthcare domain and, in particular, in the fight against COVID-19, will be discussed in this paper. An illustration of these types of drones, along with their examples, can be found in Table 3 .

\subsection{Robots}

According to the Merriam Webster dictionary [48], a robot is defined as "a machine that resembles a living creature in being capable of moving independently." As an advancement during the emergence of networked robots within the cloud, the 


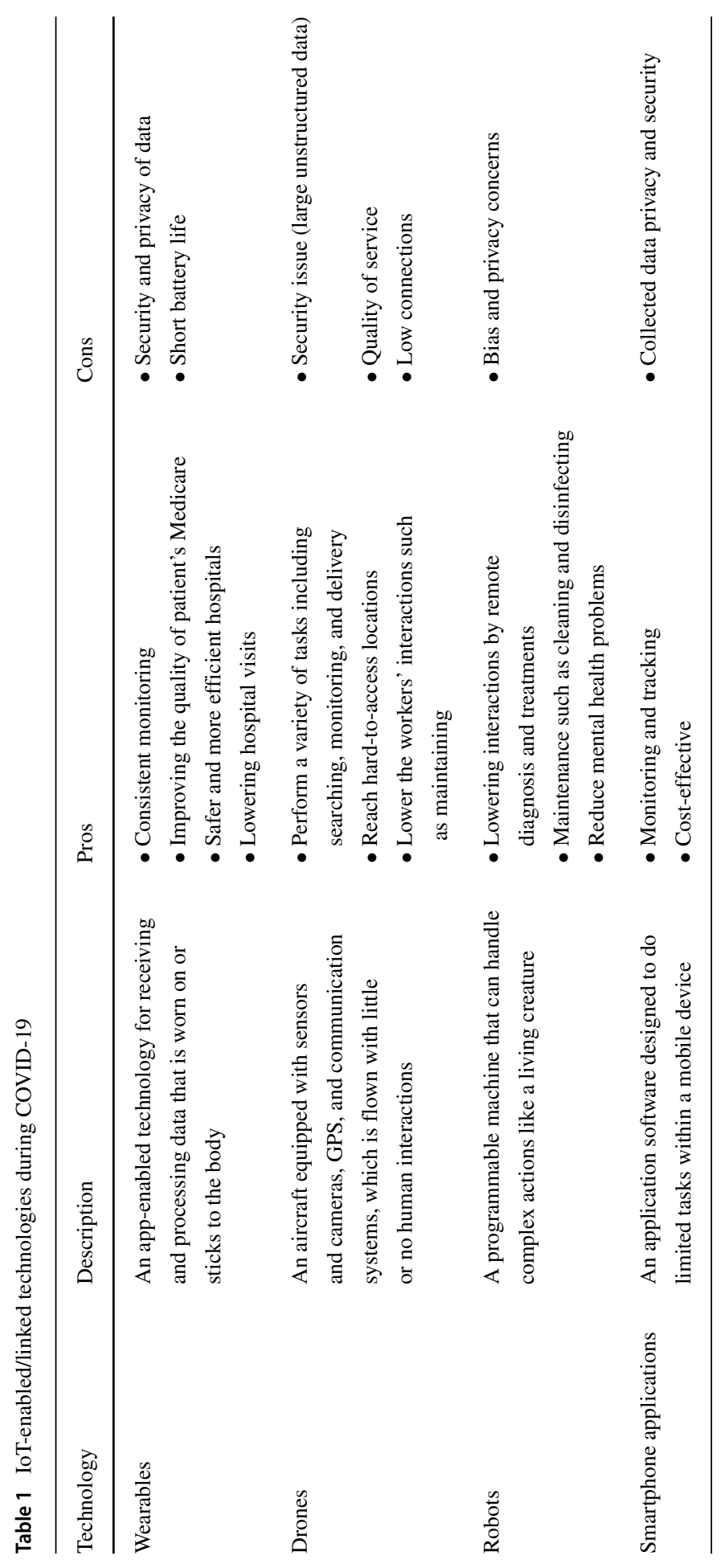




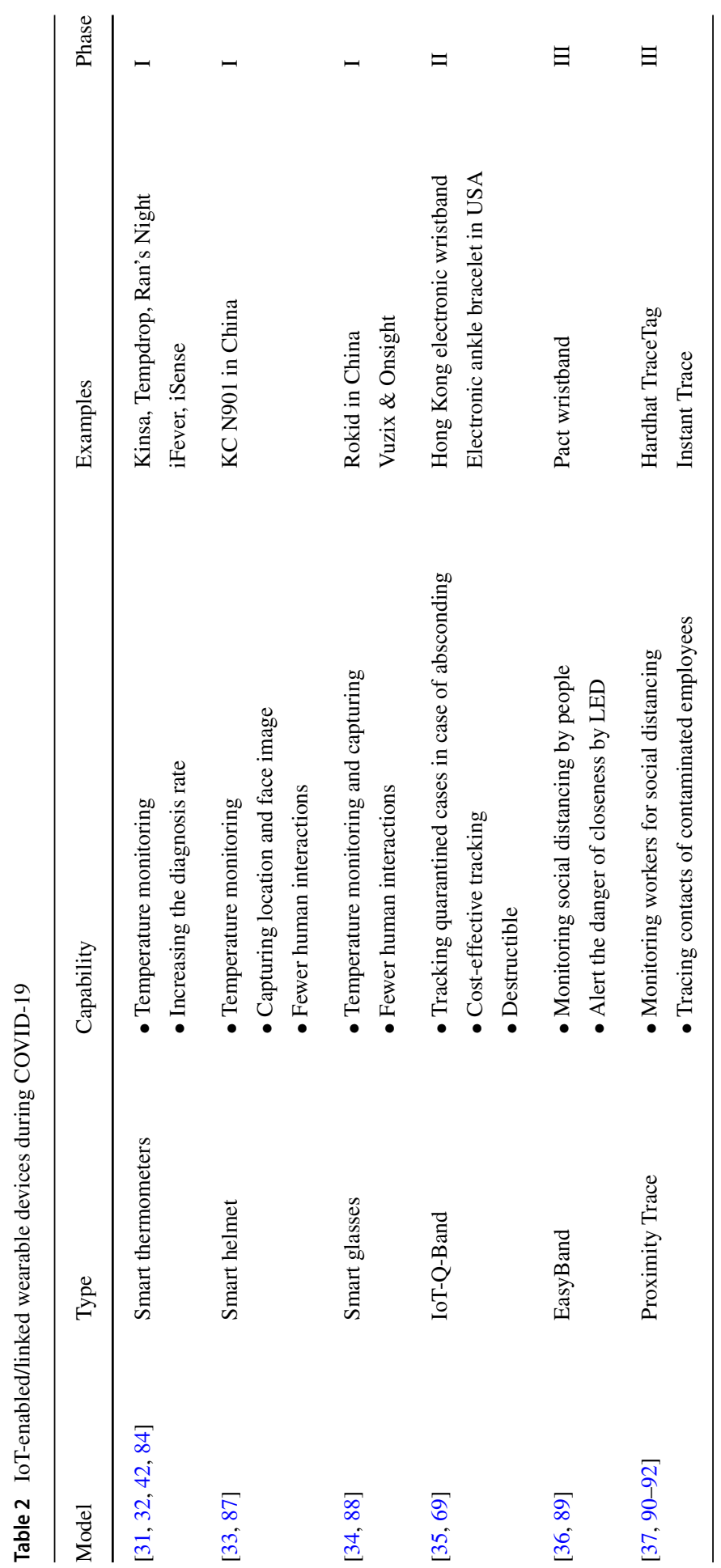




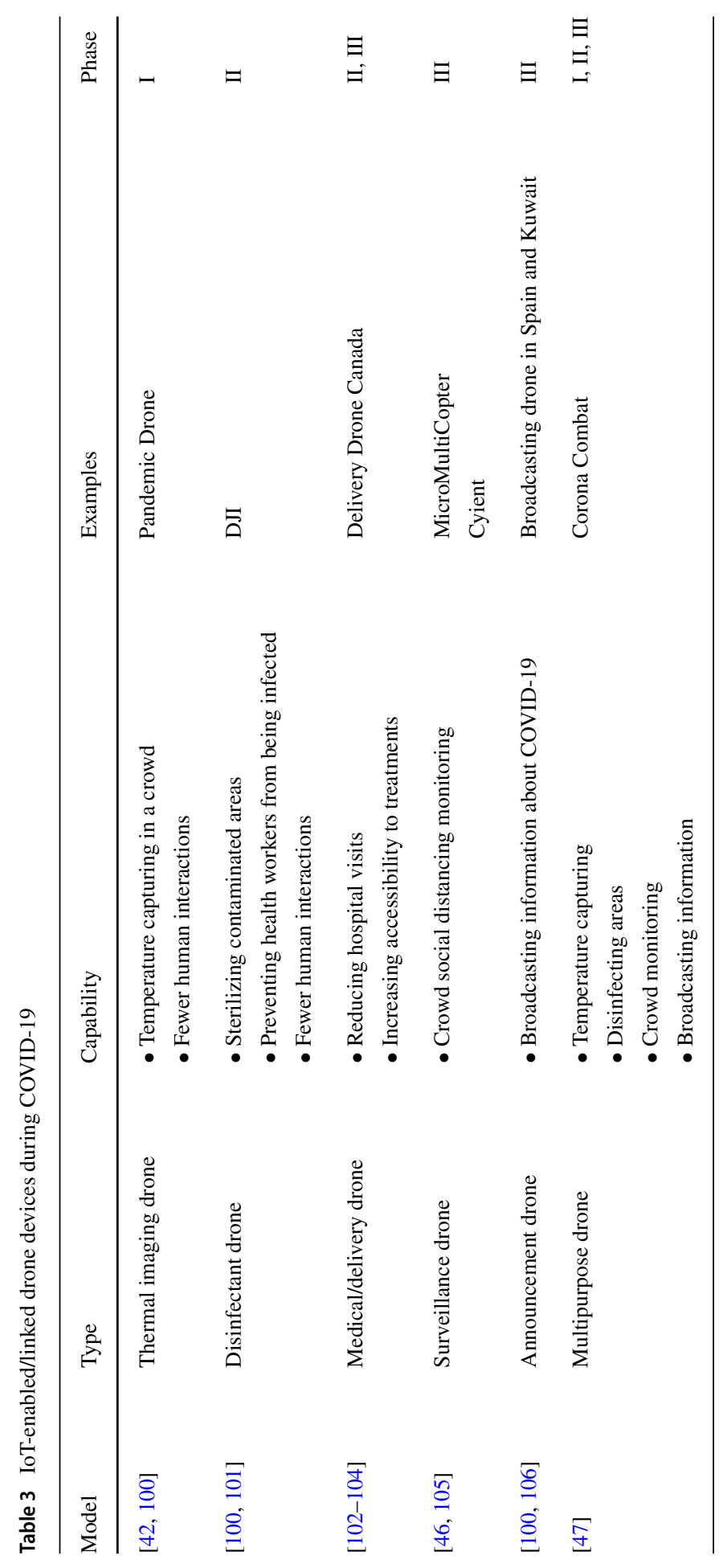


Internet of Robot Things was implemented where they can do many different tasks to make life easier [49]. Regarding the current pandemic, robots can be categorized as Autonomous robots [50], Telerobots [51], Collaborative robots [52], and Social robots [53]. Table 4 covers the fundamental aspects of these robots with examples.

\subsection{IoT Buttons}

This type of IoT device is a small, programmable button connected to the cloud through wireless communication [54]. Based on its written code on the cloud, this device can perform different repetitive tasks by pressing only one button. For example, one type of IoT button enables patients to complain if any hospital restrooms need cleaning by pressing a button only $[55,56]$. Table 5 illustrates two implementations of these buttons during COVID-19 phases.

\subsection{Smartphone Applications}

Smartphone applications are application software designed to do limited tasks within a mobile device such as a smartphone [57, 58]. Since there are 3.5 billion active smartphones in 2020, these IoT-based smartphone applications could be very efficient in various domains such as healthcare, retail, and agriculture [59-62]. Many smartphone applications have been developed for the healthcare domain, and some of them have been used in response to COVID-19, as illustrated in Table 6, namely nCapp [63], DetectaChem [64], Stop Corona [65], Social Monitoring [66], Selfie app [67], Civitas [68], StayHomeSafe [69], AarogyaSetu [70], TraceTogether [71], Hamagen [72], Coalition [73], BeAware Bahrain [74], eRouska [75], and Whatsapp [76].

\section{Phase I: Early Diagnosis}

The key to combating COVID-19 is to diagnose it early to prevent spreading the virus widely. This will substantially help healthcare providers to arrange better treatment plans, save more lives, and reduce contamination and infections [77]. The first step in the early diagnosis of COVID-19 is understanding its symptoms. According to the CDC [11], as of September 2020, COVID-19 has a wide range of symptoms including fever or chills, cough, shortness of breath or difficulty breathing, fatigue, muscle or body aches, headache, the new loss of taste or smell, sore throat, congestion or runny nose, nausea or vomiting, and diarrhea. Among them, fever or high body temperature is one of the most common symptoms of COVID-19 when the measured temperature exceeds $38{ }^{\circ} \mathrm{C}$ or $100.4^{\circ} \mathrm{F}$ [78]. IoT devices can make the detection process faster and more efficient by capturing data within their sensors and then analyzing the data for patients, healthcare providers, and authorities to diagnose, control, and ultimately stop this contagious disease [79]. Different IoT devices can be used to capture some of the aforementioned symptoms at an early stage, which will be discussed in the next subsections. 


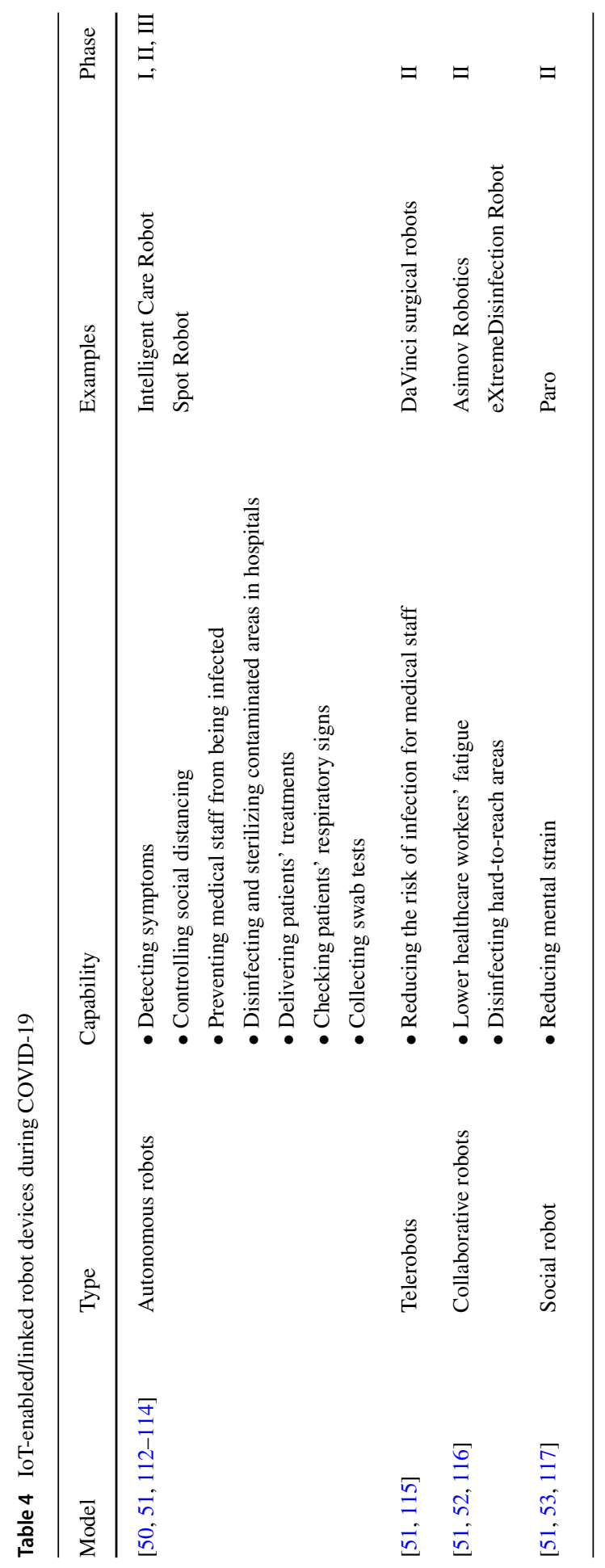


Table 5 IoT buttons during COVID-19

\begin{tabular}{lllll}
\hline Model & Type & Capability & Example & Phase \\
\hline$[118-121]$ & $(1)$ & $\bullet$ Alerting the authorities or families & Wanda QuickTouch & I \\
{$[122]$} & $(2)$ & $\bullet$ Alerting healthcare providers in case of an emergency & Sefucy & II \\
\hline
\end{tabular}

\subsection{Wearables}

Using wearable devices is considered an efficient way to respond to the need for early diagnosis during this pandemic [80]. Developing these devices has had a remarkable impact on the early detection of diseases. For example, a wearable IoT device can confirm whether respiratory signs of a patient are normal or not. With this knowledge, the patient can notice any changes in his or her health situation and then decide to make a medical appointment before any other symptoms appear [81]. In fact, the COVID-19 pandemic might be easier to fight using appropriate wearable devices.

\subsubsection{Smart Thermometers}

A wide range of IoT smart thermometers has been developed to record constant measurements of body temperatures. These low-cost, accurate, easy to use devices can be worn or stick to the skin under clothing [32]. They are usually offered in different forms such as touch, patch, and radiometric [32]. The use of these devices can be extremely helpful in the early detection of suspicious cases. Also, since the use of infrared thermometers for capturing body temperature can possibly spread the virus more due to the closeness of patients and healthcare providers, using smart thermometers is highly recommended [42].

According to [82], Kinsa's thermometers have been widely used in homes, and the producer is now able to predict the most suspicious areas (contaminated with COVID-19) in each state of the USA based on the recorded temperature of people [31, 83-85]. Other smart thermometers such as Tempdrop, Ran's Night, iFever, and iSense (shown in Fig. 1) can report body temperature at any time on a smartphone. Using these devices in people's daily lives can improve the chance of diagnosing new patients at an early stage.

\subsubsection{Smart Helmet}

During the COVID-19 pandemic, using wearable smart helmets with a thermal camera has proven to be safer compared to an infrared thermometer gun due to lower human interactions [42]. In this device, when a high temperature is detected by the thermal camera on the smart helmet, the location and the image of the person's face are taken by an optical camera. Then, they are sent to the assigned mobile device with an alarm as shown in Fig. 2, so that a health officer can distinguish the infected person, and authorities can act [33]. Additionally, Google Location History can be incorporated with the smart helmet to find the places visited by the suspected person 


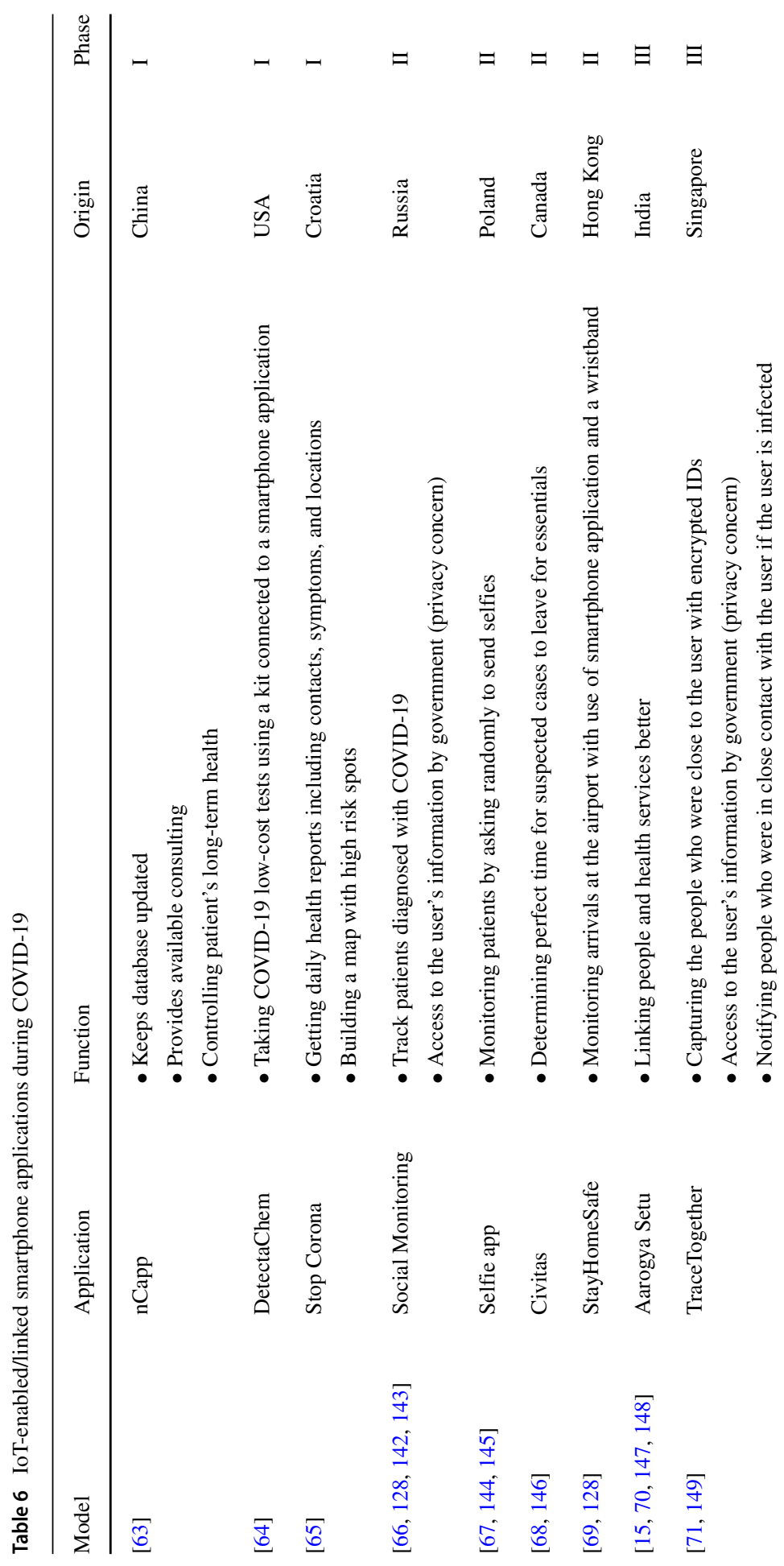




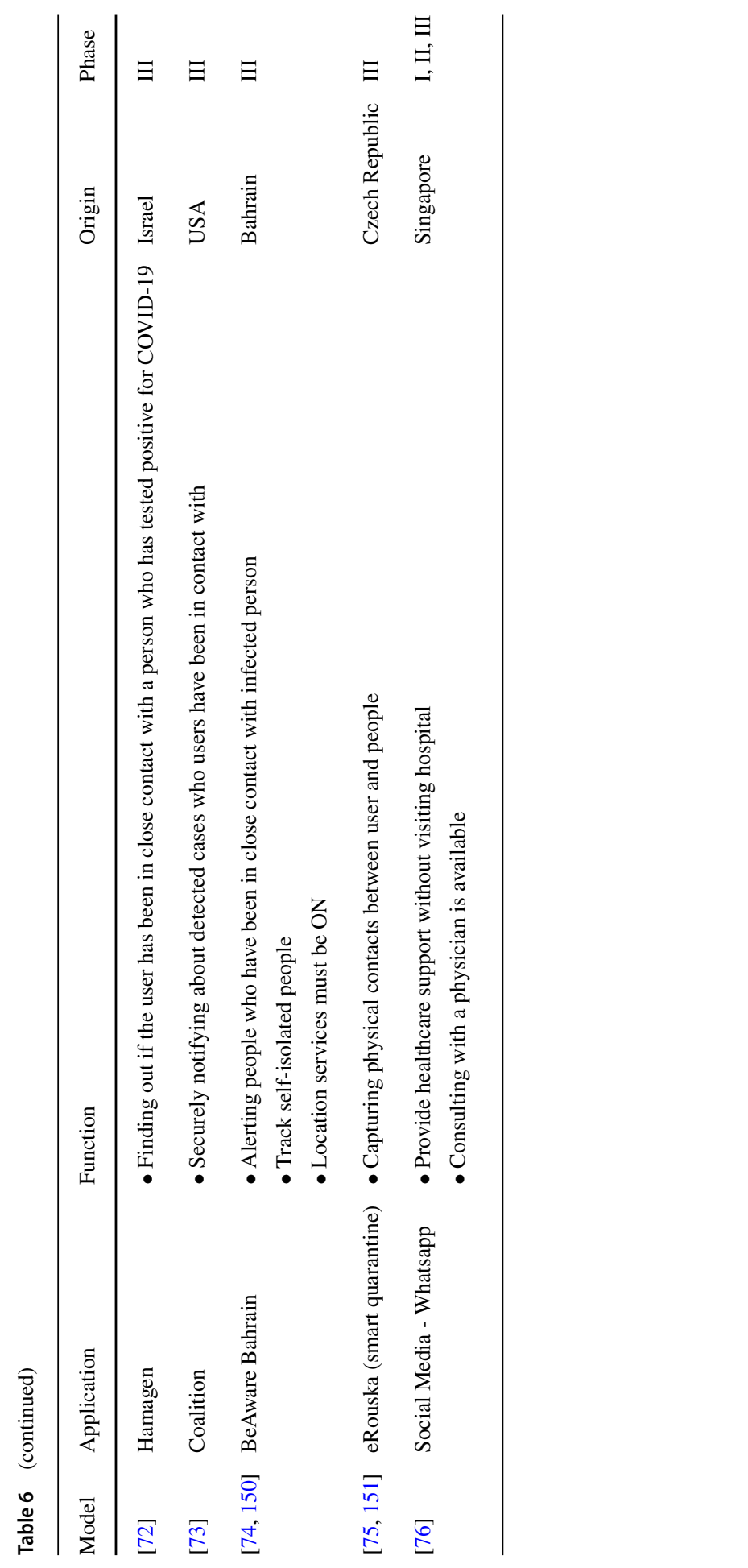




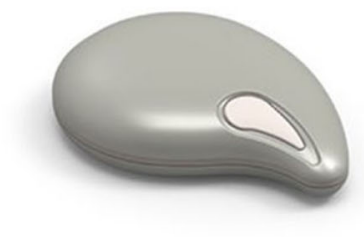

(a) Tempdrop

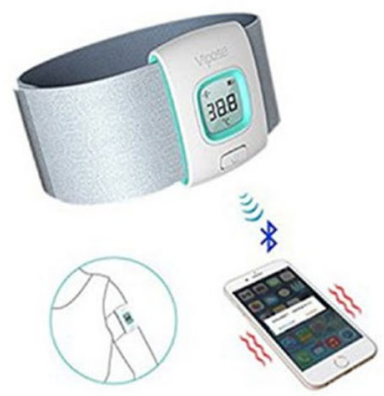

(c) iFever

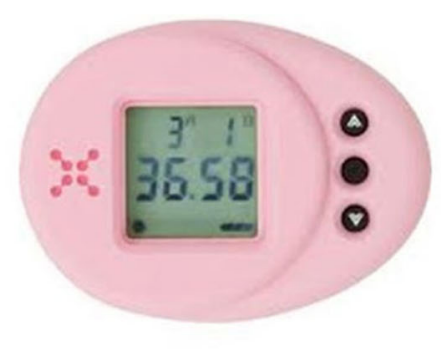

(b) Ran's Night

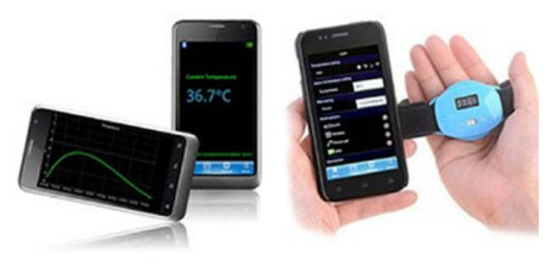

(d) iSense

Fig. 1 Wearable smart thermometers [32]

after detection [86]. Countries such as China, UAE, and Italy have implemented this wearable device to monitor crowds within $2 \mathrm{~m}$ from passers-by [87]. Interestingly, this model has shown good results. For example, KC N901 is a smart helmet produced in China that has an accuracy of 96 percent for high body temperature detection [87].

\subsubsection{Smart Glasses}

Another type of wearable device is the IoT-based smart glasses as shown in Fig. 3. In comparison with thermometer guns, smart glasses have lesser human interactions. Optical and thermal cameras have been used in smart glasses to monitor crowds [34], and the inbuilt face detection technology makes the tracking procedure easier after detecting suspicious cases. In fact, this allows detecting the identification of the suspicious case (person with a high temperature). Additionally, Google Location History can empower further actions with more reliability by capturing the places visited by the suspicious case [34]. Among different smart glasses, Rokid [88], smart glasses with infrared sensors, can monitor up to 200 people. Another example of this device is the combination of Vuzix smart glasses with the Onsight Cube thermal camera (see Fig. 4). These devices work together to monitor crowds to detect people 


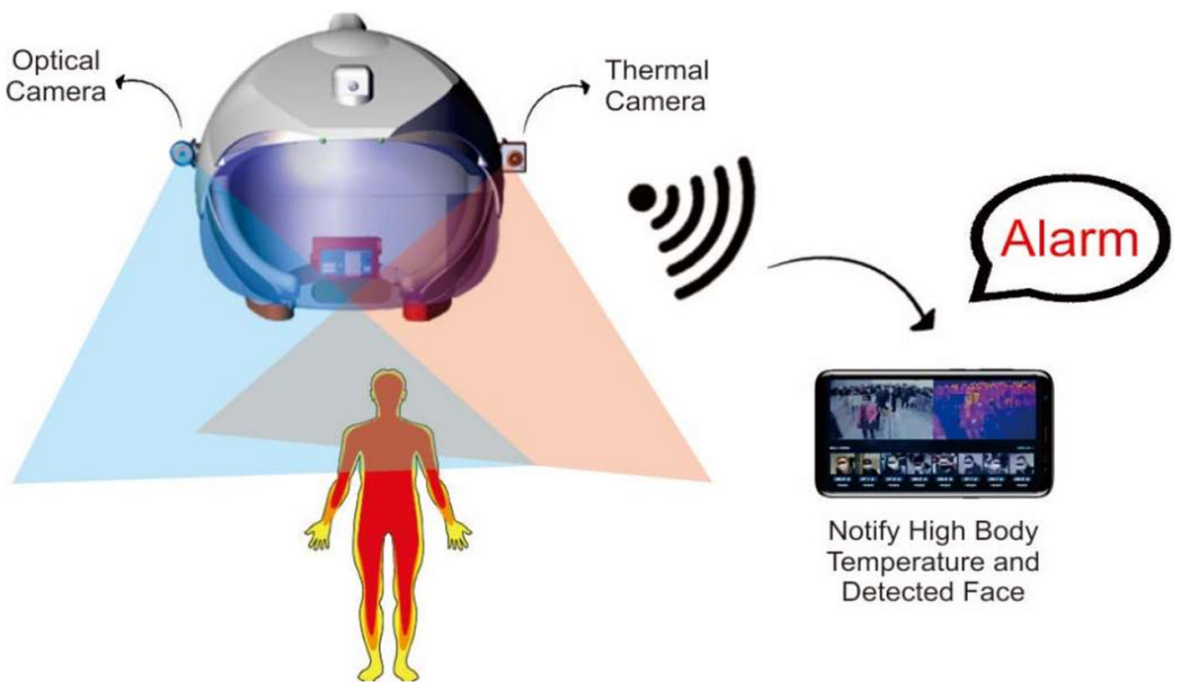

Fig. 2 Smart helmet captures temperatures using thermal and optical camera [33]

with high temperatures and provide their information to medical centers or authorities [93].

\subsection{Drones}

In general, finding infected people in a crowd is important in early diagnosis and control of COVID-19 [95]. Using unmanned aerial vehicles (UAV) and, especially, IoT-based drones is another common way to speed up the process of finding contaminated people and zones during this pandemic. Drone technology can reduce human interactions and can reach hard-to-access locations [96]. The thermal imaging drone as shown in Fig. 5 was designed for capturing the temperature of people in crowds and can be used in the early diagnosis phase. This type of drone can be

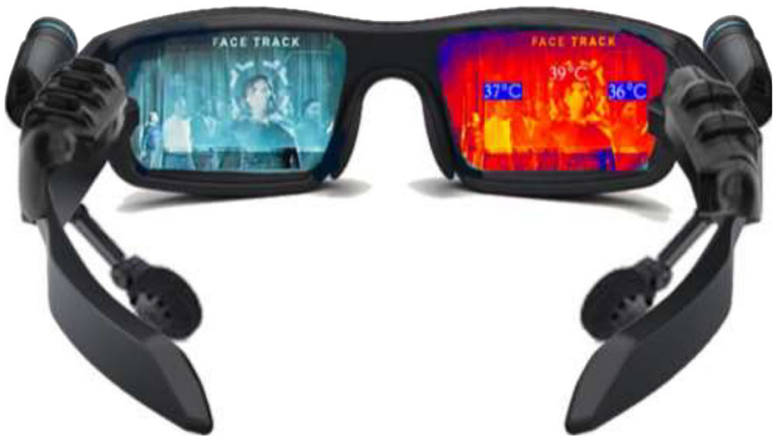

Fig. 3 Smart glasses temperature capturing [34] 


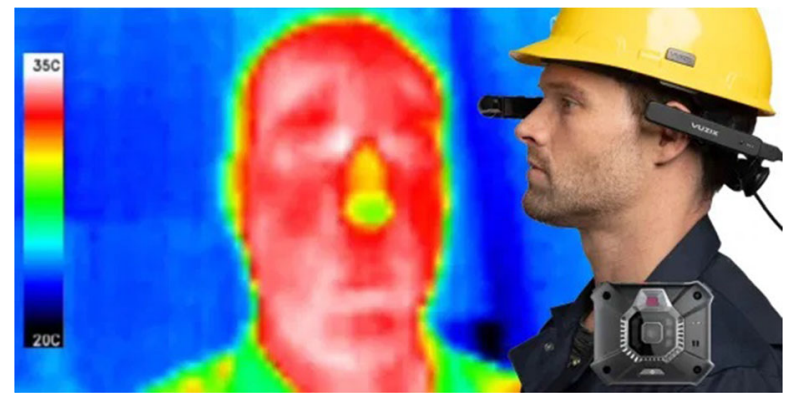

Fig. 4 Vuzix smart glass [94]

combined with Virtual Reality as a wearable device to identify people with high temperatures (fevers). This device not only reduces human interactions, but it also uses less time compared to thermometer gun devices [42]. One example of this device is the Pandemic Drone application developed by a Canadian company [97] for remote monitoring and detecting any cases of infection by capturing temperature, respiratory signs such as heart rate, and any sneezing or coughing [98, 99].

\subsection{Robots}

Using robots linked to IoT to assist early diagnosis is a remarkable use of these devices because they can help health workers by processing patients' treatments and lowering work stress levels [107]. Without the interaction of humans, the autonomous robot can help fight in all COVID-19 phases. In the first phase, it can help the process of diagnosis by collecting throat swabs samples from patients with the advantage of preventing medical staff at risk (close contact with patients) [50]. Figure 6 depicts how this process works. An example of this device, the Intelligent Care Robot, has been developed through a partnership between two companies, Vayyar Imaging [108] and Meditemi [109]. This device detects symptoms of COVID-19 in 10 seconds

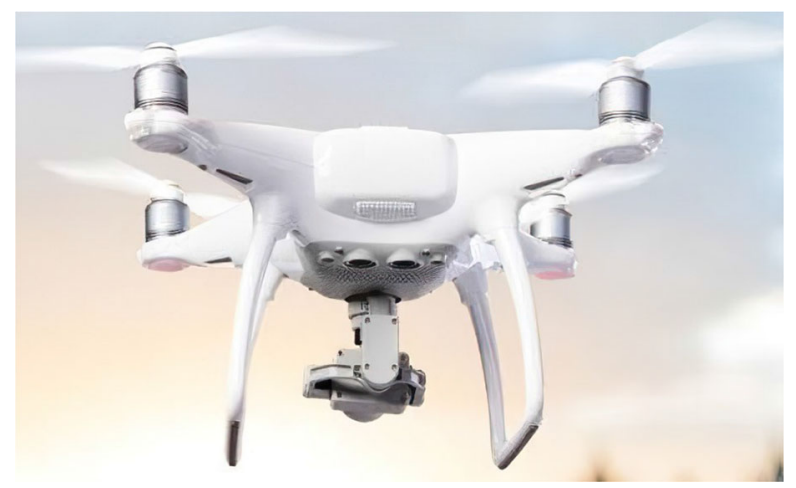

Fig. 5 Thermal imaging drone [99] 


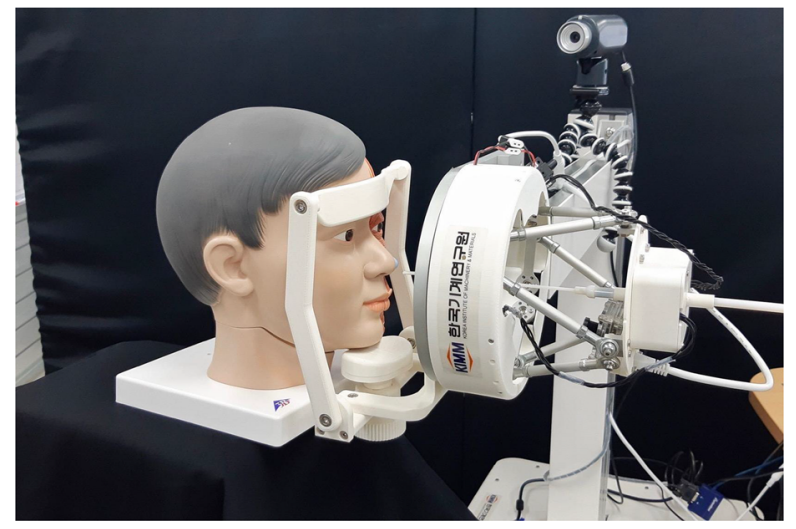

Fig. 6 Autonomous swab test robots [111]

by using touchless quick scanning of a person within a distance of $1 \mathrm{~m}$ to capture respiratory signs and temperature [110].

\subsection{IoT Buttons}

An IoT Button, in general, is a programmable device that can be used for repetitive tasks. During this pandemic, IoT buttons can play an important role in alerting the authorities or family of a patient about any contaminated area or any emergency. For example, an IoT button produced by Visionstate [118], called Wanda QuickTouch (Fig. 7), was deployed as a cleaning alert system in hospitals. They are designed for alerting authorities in case of any concerns related to essential sanitation or public safety.

\subsection{Smartphone Applications}

Smartphone applications enabled with IoT using information such as Global Positioning System (GPS) and Geographic Information System (GIS) for tracking purposes have been widely used during the COVID-19 pandemic in order to increase the chance of detecting infected people [60]. Implementing smartphone applications using the Internet of Medical Things (IoMT) will assist patients by providing them proper treatments while they are home. Additionally, it enables healthcare workers and authorities to monitor patients and the spread of disease more easily. People can upload their health information to the cloud adopted by IoT and get health advice from hospitals online. Using this platform, patients can be cured at home without expanding the contamination. It costs less than having a physical appointment at hospitals and allows the governments to take better action to manage the pandemic in the future [123]. Since the start of the pandemic, some smartphone applications have been developed for COVID-19 diagnosis and monitoring. These will be discussed in the coming sections. 


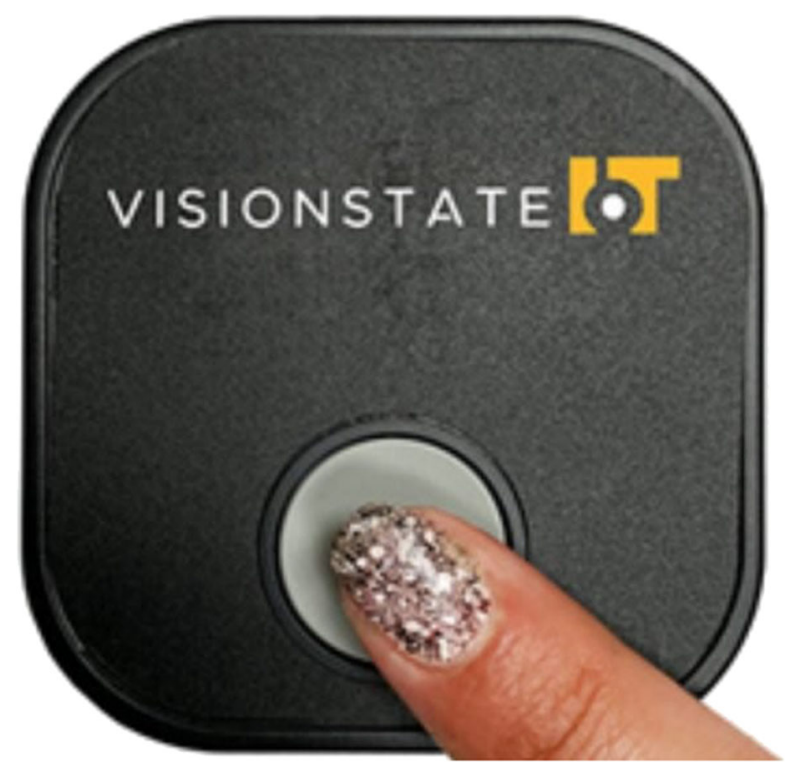

Fig. 7 Wanda QuickTouch IoT button [119]

\subsection{1 nCapp}

COVID-19 Intelligent Diagnosis and Treatment Assistant Program (nCapp) was developed in China using Internet of Medical Things on a cloud platform. This cellphone application is an automated diagnosis system with eight functions that can be selected by the user. nCapp can automatically generate a diagnosis report based on requested data and questionnaires submitted by patients. Diagnosis is categorized into three cases: confirmed, suspected, or suspicious. For the confirmed cases, there are four conditions, including "mild, moderate, severe, and critical," which are determined by a physician. Special treatments for these conditions and other types of cases are defined as well. Other positive points of this program include updating its own database in order to improve its diagnosis, making consultation possible for all health workers, making sure all patients are safe in the long term, and finally, having all these abilities publicly available. In general, by using nCapp, the diagnosis can be done faster and the spread of disease can be controlled more easily [63].

\subsubsection{MobileDetect}

The high demand for a system that can identify infected people has led to the implementation of MobileDetect, app [64]. MobileDetect which is compatible with a wide variety of smartphones, is designed to detect and control the spread of COVID-19. Using this application, users can easily take the test at home utilizing a nasal swab. The results of the test will show up on the smartphone application within 10-30 min determining the user's health situation regarding COVID-19. Then, the user can send 
the results with any additional information needed to his or her physician or healthcare professional for further action. This smartphone testing kit authorized by the Food and Drug Administration (FDA) under emergency access can be helpful during the first phase of a pandemic by lowering the spread of the virus $[64,124]$.

\subsubsection{Stop Corona}

Besides all the implementations for early case detection, another approach is having a database of captured daily health reports. The reports include contact with others, symptoms, and locations. The Stop Corona application [65] provides predictive heatmaps based on the disease spots. This application collects information from its users about their daily health status and generate reports and heatmaps based on that. The generated reports will be accessible only to health authorities. Consequently, once a user shows a new symptom and announces it, the case will appear on the new report, and ultimately authorities will be able to take proper action and detect the contaminated area more quickly due to the reported new symptoms.

\section{Phase II: Quarantine Time}

After the process of detection, it is necessary to isolate and then monitor the patients either in a hospital or at home. The quarantine does not only apply to confirmed cases but also can be considered for suspected patients and even different areas or cities or countries [12]. This is done to prevent possible transmission from suspected cases (asymptomatic cases) or areas to others. Using IoT devices in this phase could help mitigate serious challenges such as spreading the virus by monitoring patients efficiently and controlling their respiratory signs, heart rate, blood pressure, and so on [125-127].

\subsection{Wearables}

Quarantine time for confirmed or suspected cases is vital because there is a chance of spreading the virus to other people by those cases [22]. IoT wearable bands have shown promising results to prevent patients from leaving quarantine areas. Using wearable bands is a cost-effective solution for tracking cases. This device is connected to a patience's, smartphone application through Bluetooth during the quarantine period, and healthcare authorities can usually monitor all cases every 2 minutes using a web interface. Additionally, if a patient does not have the band on his or her arm or leg, or maybe leaves the quarantine area, an alert will be sent to notify the authorities, and they have permission to call the patient for clarification of the situation. Figure 8 shows a wearable band, called IoT-Q-Band, workflow process. This approach has been deployed in Hong Kong, where authorities use an electronic wristband linked with a smartphone application in order to track new arrivals at the airports for 14 days [69, 128, 129]. Similarly, authorities in the United States have implemented another type of this model using electronic ankle bracelets (ankle monitors) in order to isolate people who refuse to stay in quarantine [130, 131]. 


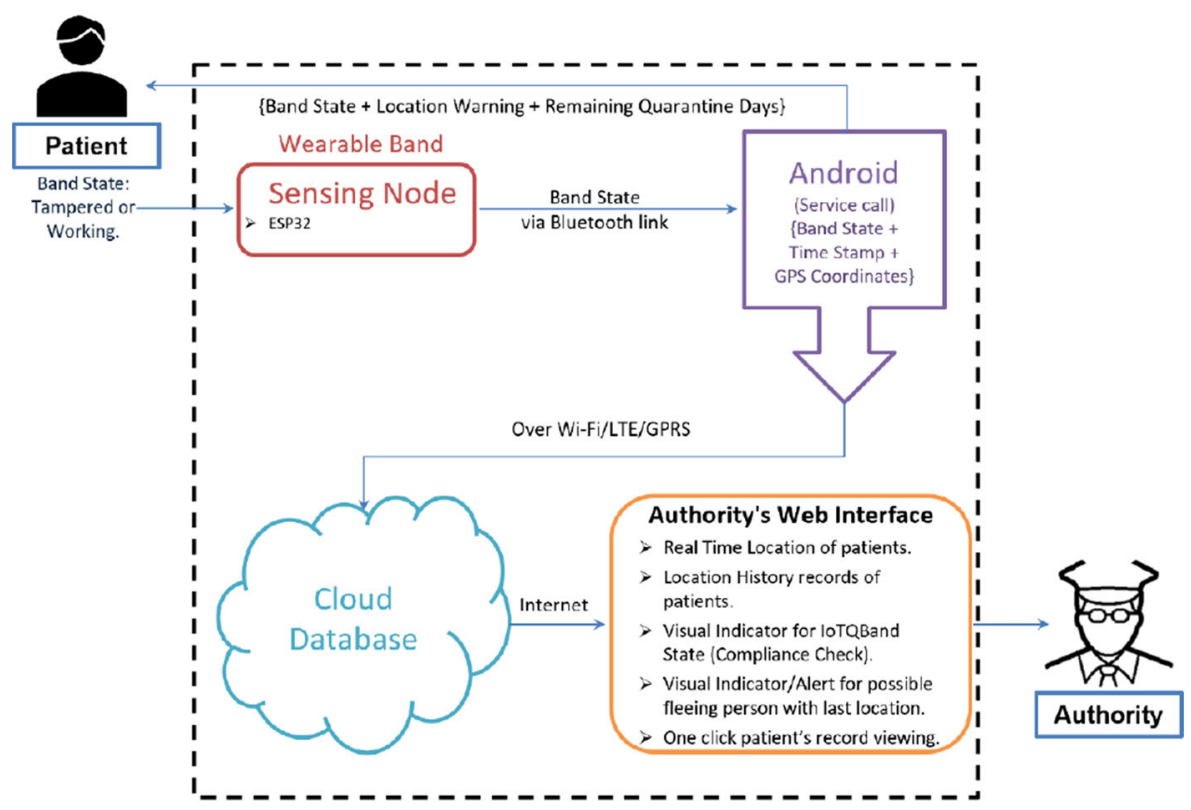

Fig. 8 IoT-Q-Band workplace classification [35]

\subsection{Drones}

Using drones plays an important role during a quarantine to decrease the number of COVID-19 cases by lowering the interaction of healthcare workers with patients and contaminated areas. For example, drones in this phase can assist healthcare workers and patients by disinfecting areas or delivering medical treatments to patients [132].

\subsubsection{Disinfectant Drone}

Keeping areas sanitized and disinfected during a quarantine is very important, and this can be achieved by using a particular type of drone, called a disinfectant drone [101] (see Fig. 9). These drones can reduce the contamination of the virus and prevent healthcare workers from getting infected. DJI company produced this drone with the ability to disinfect 100 meters in 1 hour. This type of drone has also been used in Spain for disinfecting purposes [100].

\subsubsection{Medical/Delivery Drone}

Medical drones have shown their efficiency at the early stage of COVID-19 where they transfer the COVID-19 test kits, samples, or medical supplies between labs and medical centers to eliminate human interactions. Additionally, this type of drones usually reduces hospital visits and increases access to medical care by delivering medical treatments to patients or another medical center rapidly. For example, using 


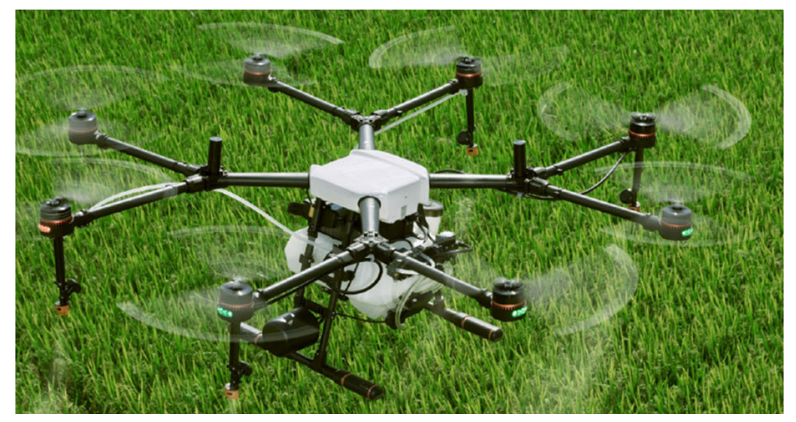

Fig. 9 Disinfectant drone [96]

medical drones in China and Ghana has increased the speed of diagnosis by cutting delivery time [102, 133]. Another type of delivery drone during COVID-19, produced by Delivery Drone Canada Inc., can move COVID-related goods, including test kits and swab tests [104]. This type of drone can be also used for other purposes such as postal and grocery services while COVID-19 confirmed cases are isolated in their homes during a quarantine [103, 134]. Figure 10 illustrates this type of drone.

\subsection{Robots}

During a quarantine, robots play an important role in keeping medical staff away from isolated patients [135]. For example, robots can be used in different ways, such as capturing respiratory signs and assisting patients with their treatments or food.

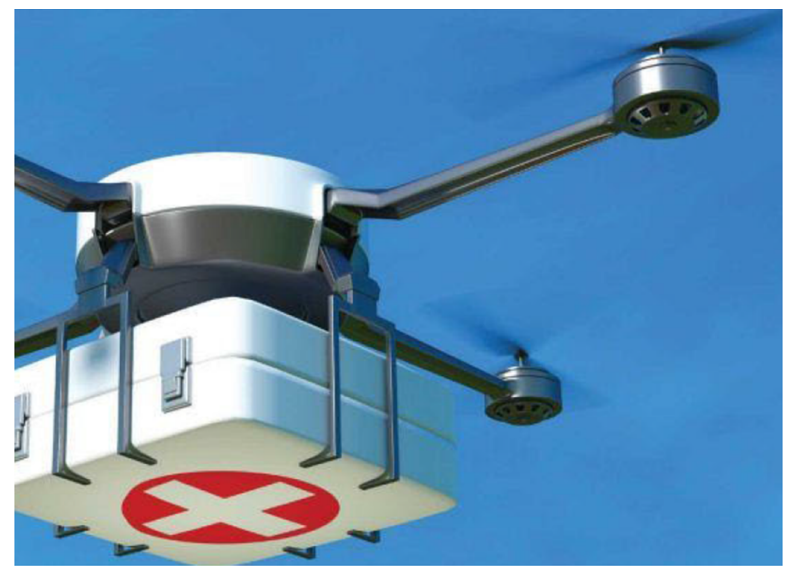

Fig. 10 Medical drone transferring medical related [96] 


\subsubsection{Telerobots}

Telerobots are usually operated remotely by a human and can provide different services such as remote diagnosis, remote surgeries, and remote treatments for the patients with no human interaction during the process [136]. For example, a nurse can measure patients' temperatures without having interactions with them by using these robots. Another example is the DaVinci surgical robot, which is operated by a surgeon while the patient is in the safe isolation of plastic sheeting. This helps to prevent infections by performing surgeries remotely [51, 115]. Figure 11 shows the actual daVinci telerobot.

\subsubsection{Collaborative Robots}

Collaborative robots, known as Cobots (Fig. 12), are recommended robots if there is a need for an operation performed by humans. They are not as beneficial as telerobots for this pandemic, but during a quarantine, this type of robot can lower healthcare workers' fatigue as well as track their interactions with patients [51]. For instance, Asimov Robotics in India is designed for a quarantine to help patients in isolated areas with tasks such as preparing food and providing medication and also preventing healthcare workers from being in that area $[52,116]$. Another example of this robot during this phase is the eXtreme Disinfection robot (XDBOT) (shown in Fig. 13) which is implemented by Nanyang Technological University in Singapore. This robot can disinfect hard to access areas, such as under a bed, and can be wirelessly operated on a mobile platform to avoid any close contact between humans and contaminated areas [52, 138].

Fig. 11 DaVinci telerobot can prevent close contact between surgeon and patient during a surgery [137]

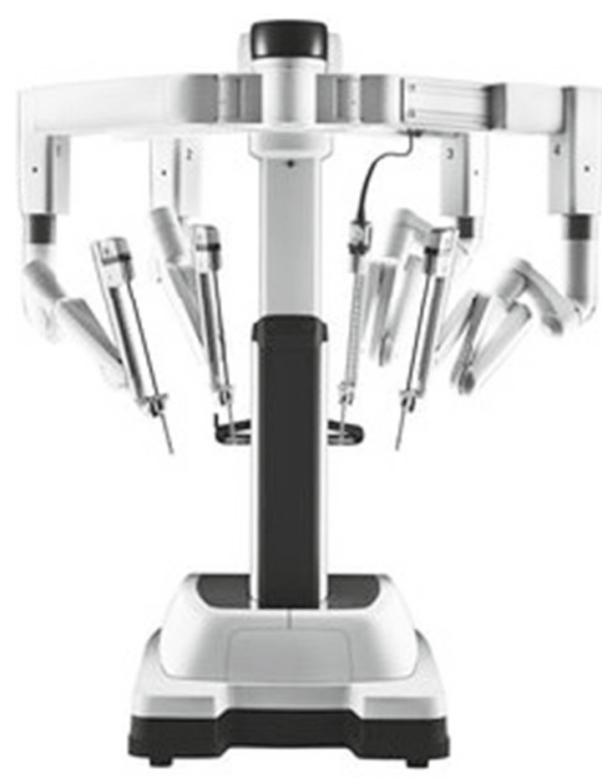




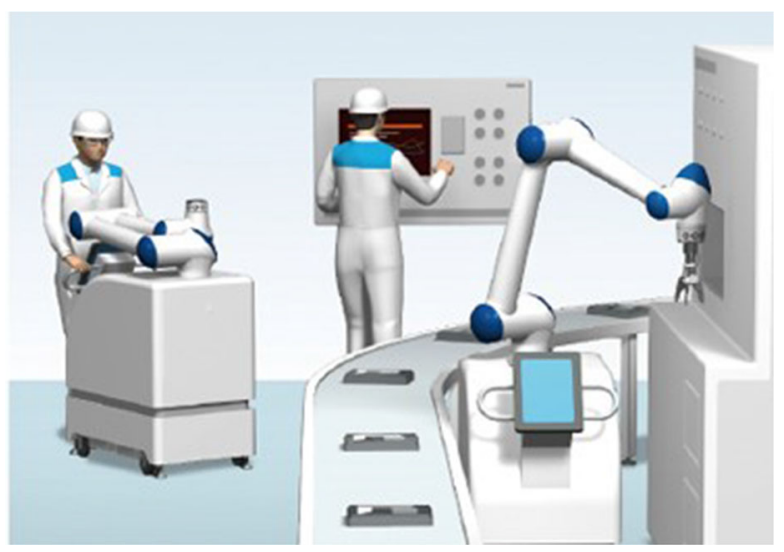

Fig. 12 Human-operated collaborative robots [139]

\subsubsection{Autonomous Robots}

Autonomous robots have been widely used during quarantines. They work with fewer or no human interactions and can be utilized in different scenarios in order to sterilize contaminated areas in hospitals, carry patients' treatments, and check their respiratory signs. These will result in decreasing the risk of infection for the healthcare workers while the patients are isolated in their rooms [51, 112]. For example, the disinfection robot created by Xenex [113] is capable of cleaning and disinfecting areas of viruses and bacteria. Figure 14 illustrates how the Xenex robot breaks down the virus using UV lights. Another example is UVD robots developed by a Danish company that are used for disinfecting hospitals with their strong UV light, which destroys the DNA of the virus [114].

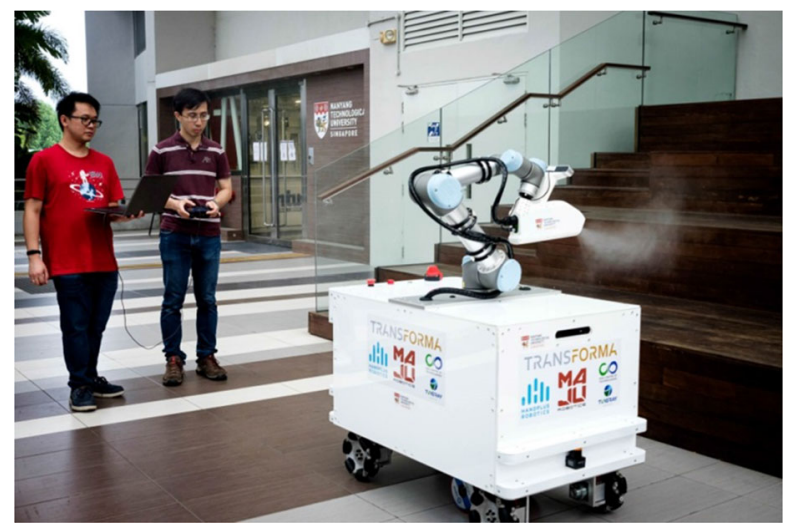

Fig. 13 XDBOT collaborative robot operating by humans for disinfecting contaminated areas [138] 


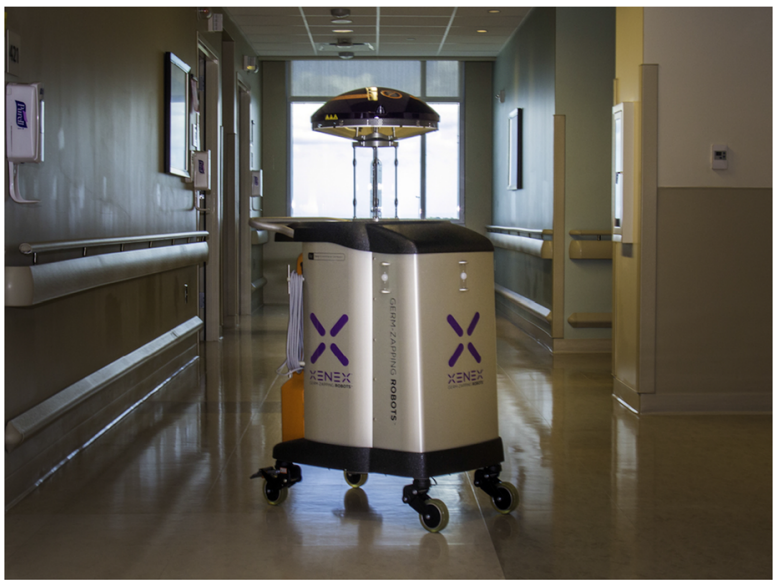

Fig. 14 Xenex disinfecting autonomous robots [140]

\subsubsection{Social Robots}

According to the CDC [141], isolating and quarantining patients can potentially cause mental health problems. To prevent this, social robots are designed to communicate with patients during that time. The functionality of these robots in this pandemic is to help reduce mental fatigue and strain during a quarantine and period of physical distancing [51]. One example of these robots is Paro [53], which can help patients during their isolation as a stress-relief device, as shown in Fig. 15.

\subsection{IoT Buttons}

The use of the IoT button in response to the COVID-19 pandemic can help to track patients during a quarantine. The Sefucy IoT button [122] was originally designed

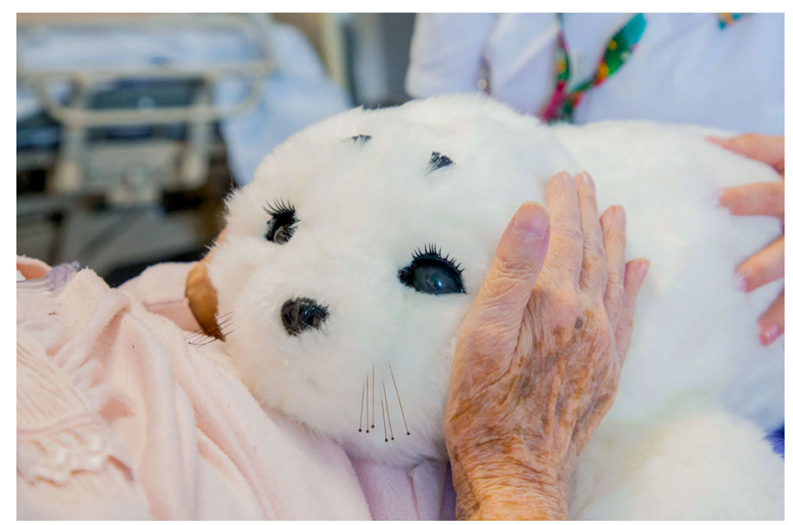

Fig. 15 Paro social robot can prevent mental effects of quarantine [53] 
for tracking lost or missing children, but with the outbreak of COVID-19, this IoT device has been used for emergency notifications during a quarantine. If the health condition of a confirmed case isolated at home gets worse, by pressing the button, a healthcare provider will be alerted, or family members will be notified in case of an emergency.

\subsection{Smartphone Applications}

The most critical part of a quarantine is keeping track of patients while they are isolated. Tracking patients using smartphones during a quarantine is another widely used approach to mitigate and control the spread of the COVID-19 virus.

\subsubsection{Social Monitoring}

In Russia, a mandatory surveillance application called Social Monitoring [66] has been developed by the government to track patients who are diagnosed with COVID-19 and must be isolated in their homes. Using this approach, authorities can track patients after the application is installed on the patients' smartphones. Patients are required to ask for a QR (Quick Response) code every time they want to leave home or quarantine areas. This code represents their identification to the authorities, which allows them to monitor patients $[128,142,143]$.

\subsubsection{Selfie App}

This application was developed in Poland integrated with Geo-location and facial recognition technology to track patients who have been told to stay at home for 14 days. Patients can refuse to install this application, but in return, they will get unexpected visits from authorities. Using the application, patients will be asked to send selfies randomly everyday [67, 144, 145].

\subsubsection{Civitas}

Civitas is a Canadian smartphone application that has been proposed to lower COVID-19's impact. Using the user's identification code, this application communicates with the authorities to request a permit that allows the user to leave the house. Civitas can assist suspected cases who need to go outside to buy essential goods in a timely manner. Furthermore, it provides a secure channel that enables physicians to contact patients to monitor their health status $[68,146]$.

\subsubsection{The StayHomeSafe}

StayHomeSafe application is considered as a combination of smartphone applications and wearable devices [69]. It has been implemented in Hong Kong where new arrivals at airports are given a wristband that can be paired with a smartphone to set the quarantine location with the advantage of geofencing technology used by the application [128]. 


\section{Phase III: After Recovery}

The restrictions put in place in response to the COVID-19 pandemic have had a devastating effect on many businesses, marketplaces, and economics. After months of locked down societies and harsh restrictions, nations are gradually and carefully opening again. This is the phase during which everyone needs to experience with extra caution. Social distancing and restrictions on physical services need to be implemented in a way to make sure the virus will not spread again [152]. In this section, we highlight the role of IoT technology in combating the COVID-19 pandemic after lockdown.

\subsection{Wearables}

Since employers are gradually bringing workers back to the work, students are returning to schools, and the economy is bouncing back during reopening, there should be some protection techniques in order to keep everyone safe from this virus. Contact tracing and social distancing are two key points to be considered for safely reopening. Wearables are the devices that can be utilized to trace users' close contacts with other people and alert them if social distancing is not maintained [153].

\subsubsection{EasyBand}

As countries gradually reopen workplaces and marketplaces after the lockdown, EasyBand [36] is one of the most effective IoT devices to make sure people are practicing social distancing. This wearable device, which is integrated with the Internet of Medical Things (IoMT), senses and captures data from other devices. EasyBand works within a specific radius and shows potential risk by its LED lights if people are very close to each other. For instance, if someone wearing an Easyband gets within 4 meters of another person, the band will start beeping to alert both and remind them to keep the appropriate distance from each other. This device has shown better results compared to smartphone apps, and it can be used without any mobile devices. Additionally, it is a cost-effective device that gives people a greater sense of safety and peace of mind. Figure 16 represents the workflow of this wearable. A similar example for this device is Pact wristband [89] (see Fig. 17), which alerts the distance between people using a vibrator and buzzer.

\subsubsection{Proximity Trace}

As industrial workers are coming back to work after the lockdown, there is an essential need for practicing social distancing between them while they work together. Proximity Trace [37] helps industrial workers maintain social distancing in practical ways. This device, which can be attached to a hard hat or body, alerts workers when they get close to each other with a loud sound. Using this device, workers will be able to concentrate on their work without worrying about contamination from the virus. Figure 18 shows how this trace can stick to the industrial workers' hard hat. Also, 


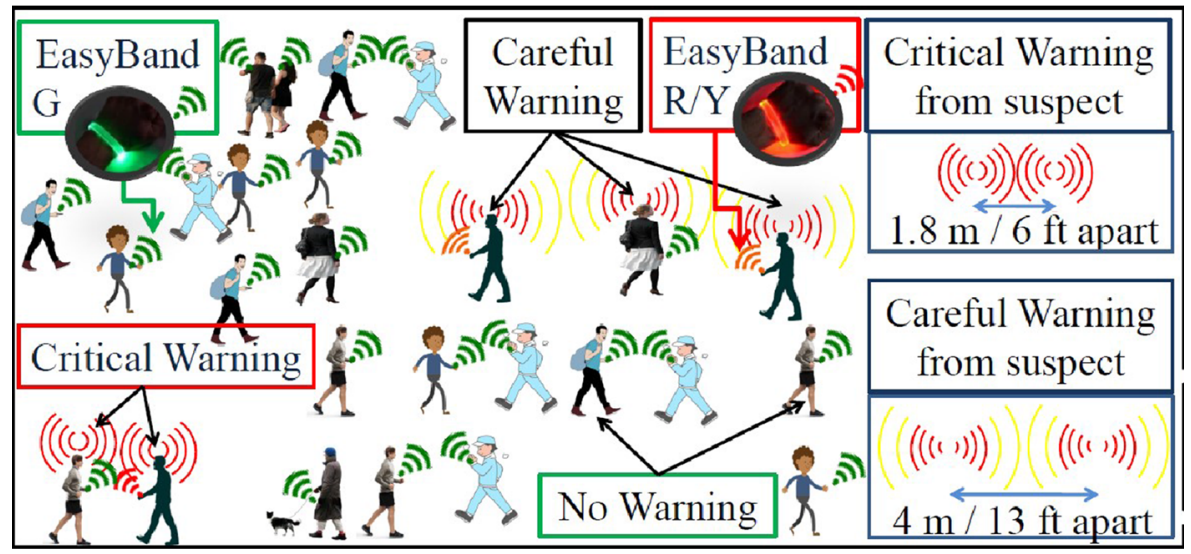

Fig. 16 EasyBand process of tracking with its designed rules [36]

Instant Trace, shown in Fig. 19, worn as a badge, has the same functionality that helps employees to maintain social distancing and trace an infected employee's contacts [92].

\subsection{Drones}

As the pandemic enters the After Recovery phase, many drones have been used in response to the reopening, which helps businesses continue working in a safe manner. Increasing social awareness by monitoring crowds and broadcasting information is the main purpose of implementing these devices during this phase [154].

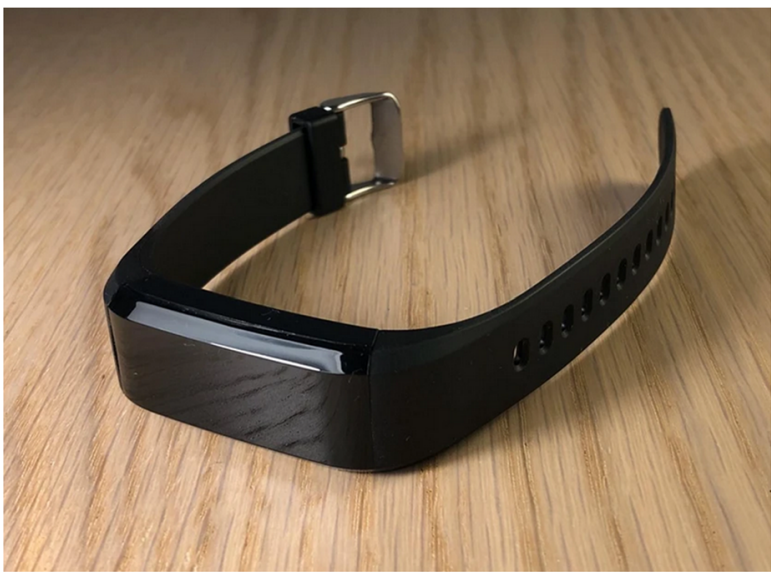

Fig. 17 Pact wristband for alerting and tracing [89] 


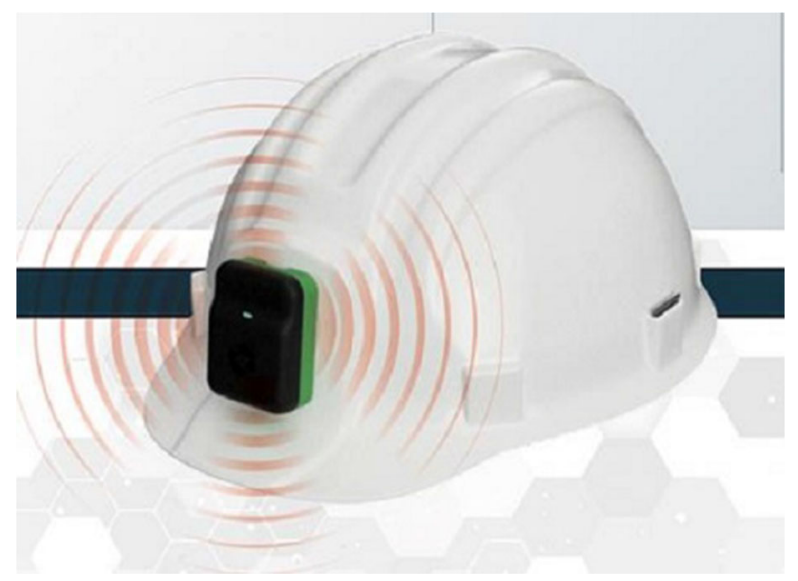

Fig. 18 Use of TraceTag on a hard hat [37]

\subsubsection{Surveillance Drone}

The Surveillance drone was designed and developed as an effective way to monitor crowds in case of people's failure to do social distancing. MicroMultiCopter, [46] made in China, and Cyient [105] from India are two types of this drone (Fig. 20). The MicroMultiCopter drone has also been equipped with speakers to announce important information from the authorities, which will be discussed in the next type of drone within this phase.

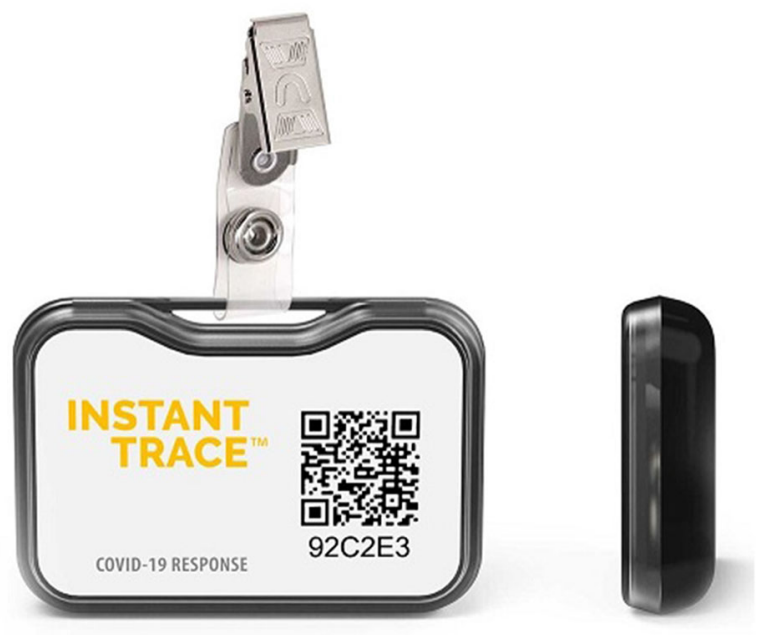

Fig. 19 Instant Trace worn as badge [37] 


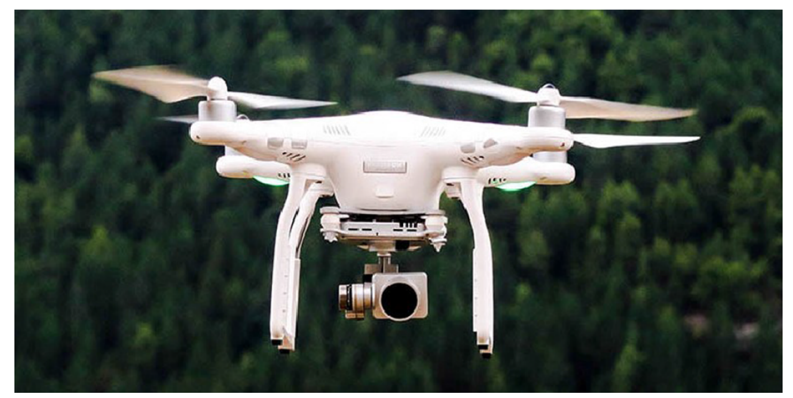

Fig. 20 Surveillance drone [155]

\subsubsection{Announcement Drone}

This type of drone is mainly designed for broadcasting in areas with low accessibility to the Internet. For example, authorities in Spain and other European countries used this type of drone to announce the practice of social distancing and other guidelines with loudspeakers $[100,106]$. Kuwait is another country that used this drone to broadcast "go home" messages to people in crowds [134] (see Fig. 21).

\subsubsection{Multipurpose Drone}

A multipurpose drone, called Corona Combat [47], has been implemented in China with the combination of all other types of drones that can cover all of the proposed goals aforementioned in the three phases at once. This drone can be deployed in any COVID-19 phase. Figure 22 shows this drone with all the characteristics from other drones.

\subsection{Robots}

As schools are opening, businesses are recovering, cars are back on the roads, and people are returning to their daily commutes, the COVID-19 pandemic is transitioning to the next phase, which is after lockdown or after recovery. In this phase,

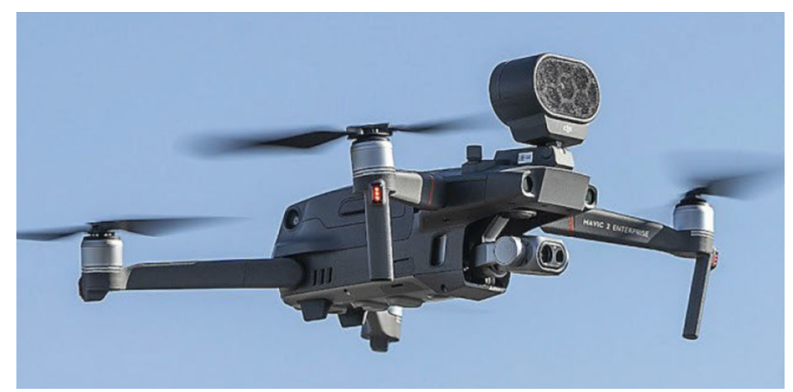

Fig. 21 Announcement drone [96] 


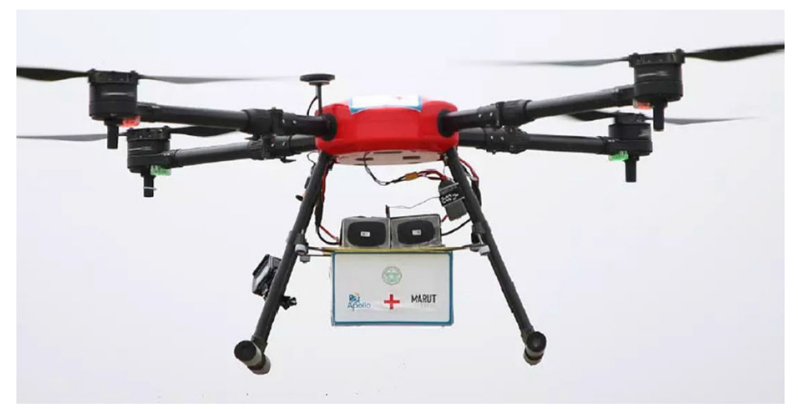

Fig. 22 All facilities at once, multipurpose drone [96]

everybody needs to know the importance of social distancing everywhere to mitigate the spread of the virus. In response to this phase of COVID-19, autonomous robots can be used to control social distancing. For instance, Spot [156], a four-legged robot designed in Singapore to be similar to a dog, reminds people to practice social distancing in public places. While this robot can be controlled remotely, it is also capable of transferring data to a web interface for further monitoring. [157]. Figure 23 is the Spot robot for monitoring the practice of social distancing.

\subsection{Smartphone Applications}

The use of IoT in healthcare is now expanding, and the major benefits are costeffectiveness, efficient monitoring, appropriate treatment, fewer mistakes, and exceptional diagnoses $[159,160]$. Some smartphone applications have been developed specifically in response to the pandemic's challenges associated with reopening, which will be covered in this section.

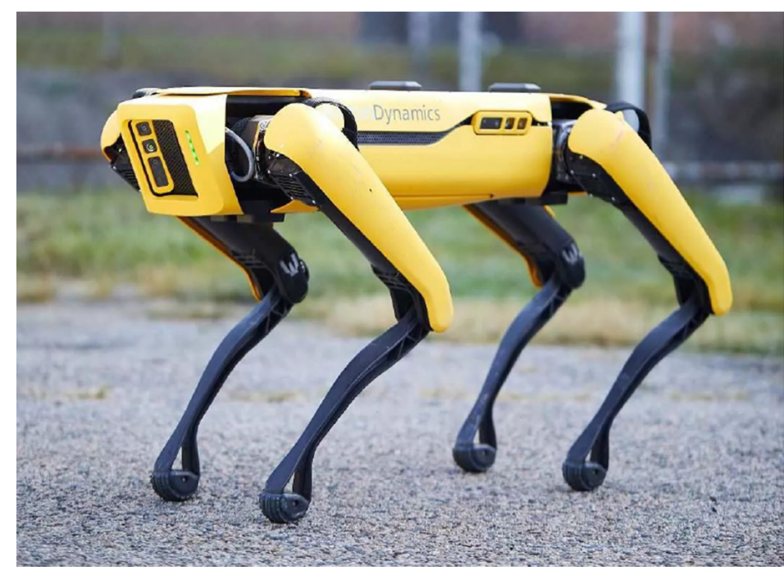

Fig. 23 "Spot" social distancing robot [158] 


\subsubsection{Aarogya Setu}

Aarogya Setu $[147,148]$ is a contact tracing application for people to use on their smartphones to increase awareness of and fight against this virus. Aarogya Setu is designed for better communication between health service providers and people. In the application, the user will be asked if he or she has any symptoms of COVID-19 or has recently traveled internationally. Analyzing the input data from the users along with their tracking information, Aarogya Setu is able to notify the user if he or she has had contact with someone who is already or later becomes a confirmed case.

\subsubsection{TraceTogether}

Singapore launched an application called TraceTogether [71] to capture data using an encrypted ID from people who were in close contact with each other. The captured data will not be used until a close contact identification is established [149, 161]. This data includes the duration of the visit, and the social distance will be stored for 21 days for contact tracing purposes in the future.

\subsubsection{Hamagen}

This contact tracing application was developed in Israel. Hamagen uses GPS technology to find out if the user has been in close contact with a person who tested positive for COVID-19. In this application, for the sake of privacy, personal data will not leave the smartphone until the user agree [72].

\subsubsection{Coalition}

Coalition [73] uses IoT technology and the blockchain [162-165] platform to provide a secure contact tracing approach. In this app, users are assigned with random IDs so that with the detection of any new cases, the users who were in close contact with those cases will be notified.

\subsubsection{BeAware Bahrain}

BeAware Bahrain is a contact tracing application implemented in Bahrain that alerts people when they are approaching contaminated areas with a detected COVID-19 case or if they were in close contact with a confirmed case. Also, this application monitors the location of self-isolated cases for 14 days and allows users to leave quarantine areas for testing appointments, which means this app is also applicable for the second phase of this pandemic [74, 150].

\subsection{6 eRouska}

This application monitors and captures any close proximity between its users. If one of the users' test is positive for COVID-19, eRouska will notify others regarding probable infection so they can take action regarding their health situation [75]. 


\subsubsection{Social Media-Whatsapp}

As of April 2020, the world had about 3.8 billion users on social media [166]. This number of users creates a great opportunity to implement telemedicine healthcare support using social media applications during this pandemic. One of the most popular applications is Whatsapp. This application provides the chance for patients to consult remotely with their physicians using virtual meetings, which will lead to decreasing hospital visits by patients. Using this method is applicable to all phases during the COVID-19 pandemic [167].

\section{Discussion and Future Work}

COVID-19 is considered both a global health crisis and an international economic threat. The restrictions put in place in response to the COVID-19 pandemic has had a devastating effect on many businesses, marketplaces, economics, society, and our lives. The full health, social, and economic consequences of this pandemic and its restrictions will take time to be fully recognized and quantified; however, there are many ongoing efforts in the research and industrial communities to utilize different technologies to detect, treat, and trace the virus to mitigate its impacts. Internet of Things (IoT) technology has shown promising results in early detection, quarantine time, and after recovery from COVID-19; however, as we learn more about the virus and its behavior, we should adjust and improve our approaches in different phases. For example, it would be interesting to integrate Artificial Intelligence (AI) and IoT technology in order to use AI power to minimize interactions between healthcare workers and patients in all phases. Another example is using touchless technology with the help of other inputs (such as gesture and voice) that could efficiently lower the spread of the disease and end the pandemic sooner [168]. Further research needs to be done on convincing confirmed cases of COVID-19 to remain in quarantine to mitigate the spread of the virus. Moreover, how can IoT devices help isolated patients efficiently in their daily lives. After lockdown, as businesses and marketplaces are opening gradually, how can IoT devices be incorporated in businesses to cover both safety and efficiency. Answers to those questions will attract considerable attention in both research and industrial disciplines and open new research avenues in this area.

One of the main concerns about using IoT devices in different phases of this pandemic is the privacy issue when patients are asked to share their information. Definitely, this is a big concern for every patient, so defining secure channels for communications or utilizing different encryption techniques before sharing private information would be possible research areas.

Having IoT-enabled Smart Cities can be extremely helpful in combating the current and any future pandemic through collaboration between medical centers, cities, etc. [169]. Along with aforementioned IoT applications, Allam et al. [170] emphasize the importance of the concept of Smart City networks while the world is struggling with the COVID-19 pandemic. Smart City infrastructure can help people maintain social distancing by the implementation of smart transportation systems including crowd monitoring, smart parking, and traffic re-routing [171]. As a part of smart 
living in the Smart City, smart home IoT-based technologies can also reduce the infection rate of COVID-19. For instance, smart home doorbells and security systems can be implemented to prevent users from touching surfaces, so there will not be any contamination of the virus from touching those surfaces $[15,172,173]$.

\section{Conclusion}

While the world is struggling with the COVID-19 pandemic, many technologies have been implemented to fight against this disease. One of these technologies is the Internet of Things (IoT), which has been widely used in the healthcare industry. During the COVID-19 pandemic, this technology has shown very encouraging results dealing with this disease. For this paper, we conducted a survey on the recent proposed IoT devices aiming to assist healthcare workers and authorities during the COVID-19 pandemic. We reviewed the IoT-related technologies and their implementations in three phases, including "Early Diagnosis," "Quarantine Time," and "After Recovery." For each phase, we evaluated the role of IoT-enabled/linked technologies including wearables, drones, robots, IoT buttons, and smartphone applications in combating COVID-19. IoT technology can be extremely efficient for this pandemic, but it is also critical to consider the privacy of data. By implementing IoT technology properly in a secure way, more patients, with peace of mind, can participate in their treatment using IoT devices. As a result, authorities and healthcare workers can better respond to pandemics. Consequently, the impact of these types of diseases, including infections, hospitalizations, and death rate, can be significantly reduced.

\section{References}

1. Ashton K, et al. (2009) That 'internet of things' thing. RFID J 22(7):97-114

2. Ali ZH, Ali HA, Badawy MM (2015) Intenet of things (IoT): definitions, challenges and recent research directions. Int J Comput Appl 128(1):37-47

3. HaddadPajouh H, Dehghantanha A, Parizi RM, Aledhari M, Karimipour H (2019) A survey on internet of things security: requirements, challenges, and solutions. Internet of Things 3:100-129

4. da Costa CA, Pasluosta CF, Eskofier B, da Silva DB, da Rosa Righi R (2018) Internet of health things: toward intelligent vital signs monitoring in hospital wards. Artif Intell Med 89:61-69

5. Islam SMR, Kwak D, Kabir MDH, Hossain M, Kwak K-S (2015) The internet of things for health care: a comprehensive survey. IEEE Access 3:678-708

6. Hu F, Xie D, Shen S (2013) On the application of the internet of things in the field of medical and health care. In: 2013 IEEE International Conference on Green Computing and Communications an IEEE Internet of Things and IEEE Cyber, Physical and Social Computing. IEEE, pp 2053-2058

7. Qi J, Yang P, Min G, Amft O, Dong F, Xu L (2017) Advanced internet of things for personalised healthcare systems: a survey. Pervasive Mob Comput 41:132-149

8. IoT in healthcare market. (2020) https://www.marketsandmarkets.com/Market-Reports/iot-healthcaremarket-160082804.html. Accessed June 29, 2020

9. Lovelace Jr B (2020) Scientists say the coronavirus is at least as deadly as the 1918 flu pandemic. https://www.cnbc.com/berkeley-lovelace-jr/. Accessed September 5, 2020

10. WHO (2020) Coronavirus disease (COVID-19). https://bit.ly/2ZU5x08. Accessed July 09, 2020

11. Symptoms of coronavirus. (2020) https://www.cdc.gov/coronavirus/2019-ncov/symptoms-testing/ symptoms.html. Accessed June 26, 2020 
12. CDC (2020) Quarantine if you might be sick. https://www.cdc.gov/coronavirus/2019-ncov/ if-you-are-sick/quarantine.html. Accessed July 04, 2020

13. Wang W, Tang J, Wei F (2020) Updated understanding of the outbreak of 2019 novel coronavirus (2019-nCoV) in Wuhan, China. J Med Virol 92(4):441-447

14. Peeri NC, Shrestha N, Rahman MS, Zaki R, Tan Z, Bibi S, Baghbanzadeh M, Aghamohammadi N, Zhang W, Haque U (2020) The SARS, MERS and novel coronavirus (COVID-19) epidemics, the newest and biggest global health threats: what lessons have we learned?. International Journal of Epidemiology

15. Singh RP, Javaid M, Haleem A, Suman R (2020) Internet of things (IoT) applications to fight against COVID-19 pandemic. Diabetes \& Metabolic Syndrome: Clinical Research \& Reviews

16. Ting DSW, Carin L, Dzau V, Wong TY (2020) Digital technology and COVID-19. Nat Med 26(4):459-461

17. To KK-W, Tsang OT-Y, Yip CC-Y, Chan K-H, Wu T-C, Chan JM-C, Leung W-S, Chik TS-H, Choi CY-C, Kandamby DH, et al. (2020) Consistent detection of 2019 novel coronavirus in saliva. Clin Infect Dis

18. Xing Y, Mo P, Xiao Y, Zhao O, Zhang Y, Wang F (2020) Post-discharge surveillance and positive virus detection in two medical staff recovered from coronavirus disease 2019 (COVID-19), China, January to February 2020. Eurosurveillance 25(10):2000191

19. Zhang SX, Wang Y, Rauch A, Wei F (2020) Unprecedented disruption of lives and work: health, distress and life satisfaction of working adults in China one month into the COVID-19 outbreak. Psychiatry Res 112958

20. Christaki E (2015) New technologies in predicting, preventing and controlling emerging infectious diseases. Virulence 6(6):558-565

21. Phelan AL, Katz R, Gostin LO (2020) The novel coronavirus originating in Wuhan, China: challenges for global health governance. Jama 323(8):709-710

22. Nussbaumer-Streit B, Mayr V, Dobrescu AI, Chapman A, Persad E, Klerings I, Wagner G, Siebert U, Christof C, Zachariah C, et al. (2020) Quarantine alone or in combination with other public health measures to control COVID-19: a rapid review. Cochrane Database Syst Rev (4)

23. Rahman MS, Peeri NC, Shrestha N, Zaki R, Haque U, Ab Hamid SH (2020) Defending against the novel coronavirus (COVID-19) outbreak: how can the internet of things (IoT) help to save the world?. Health Policy and Technology

24. CDC (2020) Prevent the spread of COVID-19 if you are sick. https://bit.ly/3hj7tq1. Accessed July 20, 2020

25. Lee BY (2020) Can you get COVID-19 coronavirus twice? here is an update on reinfection. https://www.forbes.com/sites/brucelee/2020/07/19/can-you-get-covid-19-coronavirus-twice-here-isan-update-on-reinfection/\#6499ed737cbf. Accessed July 20, 2020

26. Hayes A (2020) Wearable technology. https://www.investopedia.com/terms/w/wearable-technology. asp

27. Research J Smart wearables market to generate \$53bn hardware revenues by 2019. https://www. juniperresearch.com/press/press-releases/smart-wearables-market-to-generate-53bn-hardware. Accessed July 04, 2020

28. Wright R, Keith L (2014) Wearable technology: if the tech fits, wear it. J Electron Resour Med Libr 11(4):204-216

29. Berglund ME, Duvall J, Dunne LE (2016) A survey of the historical scope and current trends of wearable technology applications. In: Proceedings of the 2016 ACM International Symposium on Wearable Computers. pp 40-43

30. Healthcare spend in wearables to reach $\$ 60$ billion by 2023 , as monitoring devices \& hearables become 'must haves' in delivering care. (2020) https://www.juniperresearch.com/press/ press-releases/healthcare-spend-in-wearables-reach-60-bn-2023. Accessed July 04, 2020

31. Chamberlain SD, Singh I, Ariza CA, Daitch AL, Philips PB, Dalziel BD (2020) Real-time detection of COVID-19 epicenters within the United States using a network of smart thermometers. medRxiv

32. Tamura T, Huang M, Togawa T (2018) Current developments in wearable thermometers. Adv Biomed Eng 7:88-99

33. Mohammed M, Syamsudin H, Al-Zubaidi S, AKS RR, Yusuf E (2020) Novel COVID-19 detection and diagnosis system using IoT based smart helmet. International Journal of Psychosocial Rehabilitation 24(7):2296-2303 
34. Mohammed M, Hazairin NA, Syamsudin H, Al-Zubaidi S, Sairah AK, Mustapha S, Yusuf E (2020) 2019 novel coronavirus disease (COVID-19): detection and diagnosis system using IoT based smart glasses. International Journal of Advanced Science and Technology 29(7 Special Issue):954-960

35. Singh VK, Chandna H, Kumar A, Kumar S, Upadhyay N, Utkarsh K (2020) IoT-Q-Band: a low cost internet of things based wearable band to detect and track absconding COVID-19 quarantine subjects. EAI Endorsed Transactions on Internet of Things

36. Tripathy AK, Mohapatra AG, Mohanty SP, Kougianos E, Joshi AM, Das G (2020) Easyband: a wearable for safety-aware mobility during pandemic outbreak. IEEE Consumer Electronics Magazine

37. Contact tracing IoT solution. (2020) https://bit.ly/2B60rF2. Accessed June 06, 2020

38. Kardasz P, Doskocz J, Hejduk M, Wiejkut P, Zarzycki H (2016) Drones and possibilities of their using. J Civil Environ Eng 6(3):1-7

39. Naughton R (2007) Remote piloted aerial vehicles: an anthology. Centre for Telecommunications and Information Engineering, Monash University, 3

40. Rouse M (2019) Drone (UAV). https://bit.ly/2ZHuonE. Accessed July 04, 2020

41. Nayyar A, Nguyen B-L, Nguyen NG (2020) The internet of drone things (IoDT): future envision of smart drones. In: First International Conference on Sustainable Technologies for Computational Intelligence. Springer, pp 563-580

42. Mohammed M, Hazairin NA, Al-Zubaidi S, AK S, Mustapha S, Yusuf E (2020) Toward a novel design for coronavirus detection and diagnosis system using IoT based drone technology. Int $\mathbf{J}$ Psychosoc Rehabil 24(7):2287-2295

43. Shaw KK, Vimalkumar R (2020) Design and development of a drone for spraying pesticides, fertilizers and disinfectants. Engineering Research \& Technology (IJERT)

44. Zema NR, Natalizio E, Ruggeri G, Poss M, Molinaro A (2016) Medrone: on the use of a medical drone to heal a sensor network infected by a malicious epidemic. Ad Hoc Netw 50:115-127

45. Ding G, Wu Q, Zhang L, Lin Y, Tsiftsis TA, Yao Y-D (2018) An amateur drone surveillance system based on the cognitive internet of things. IEEE Commun Mag 56(1):29-35

46. Marr B (2020) Robots and drones are now used to fight COVID-19

47. Delhi civic body begins thermal screening people on balconies with drones. (2020) https://www. ndtv.com/delhi-news/coronavirus-delhi-civic-body-using-drones-to-check-temperature-of-people-onbalconies-220983. Accessed June 15, 2020

48. Robot. (2020) https://www.merriam-webster.com/dictionary/robot. Accessed July 04, 2020

49. Ray PP (2016) Internet of robotic things: concept, technologies, and challenges. IEEE Access 4:9489-9500

50. Editors M (2020) Automated robot takes swabs for safe COVID-19 testing. https://www.medgadget. com/2020/06/automated-robot-takes-swabs-for-safe-covid-19-testing.html. Accessed June 24, 2020

51. Tavakoli M, Carriere J, Torabi A (2020) Robotics, smart wearable technologies, and autonomous intelligent systems for healthcare during the COVID-19 pandemic: an analysis of the state of the art and future vision. Advanced Intelligent Systems, 2000071

52. Tao M (2020) Cobots v COVID: How universal robots and others are helping in the fight against coronavirus. https://bit.ly/2ATJ5vH. Accessed June 24, 2020

53. Knibbs K (2020) There's no cure for COVID-19 loneliness, but robots can help. https://www.wired. com/story/covid-19-robot-companions/. Accessed July 10, 2020

54. Chai PR, Zhang H, Baugh CW, Jambaulikar GD, McCabe JC, Gorman JM, Boyer EW, Landman A (2018) Internet of things buttons for real-time notifications in hospital operations: proposal for hospital implementation. J Med Int Res 20(8):e251

55. AWS IoT button. https://aws.amazon.com/iotbutton/. Accessed July 04, 2020

56. Chai PR, Zhang H, Jambaulikar GD, Boyer EW, Shrestha L, Kitmitto L, Wickner PG, Salmasian H, Landman AB (2019) An internet of things buttons to measure and respond to restroom cleanliness in a hospital setting: descriptive study. J Med Int Res 21(6):e13588

57. Mobile application (mobile app). (2018) https://www.techopedia.com/definition/2953/mobileapplication-mobile-app. Accessed July 04, 2020

58. Kamaludeen NBA, Lee SP, Parizi RM (2019) Guideline-based approach for IoT home application development. In: 2019 International Conference on Internet of Things (iThings) and IEEE Green Computing and Communications (GreenCom) and IEEE Cyber, Physical and Social Computing (CPSCom) and IEEE Smart Data (SmartData). pp 929-936 
59. Turner A (2020) How many smartphones are in the world

60. El Khaddar MA, Boulmalf M (2017) Smartphone: the ultimate IoT and IoE device. Smartphones from an Applied Research Perspective, 137

61. Sinha D (2019) IoT-based mobile applications and their impact on user experience. https://www. iotforall.com/mobile-iot/. Accessed July 04, 2020

62. Parizi RM, Guo L, Bian Y, Azmoodeh A, Dehghantanha A, Choo K-KR (2018) CyberPDF: smart and secure coordinate-based automated health PDF data batch extraction. In: 2018 IEEE/ACM International Conference on Connected Health: Applications, Systems and Engineering Technologies (CHASE). IEEE, pp 106-111

63. Bai L, Yang D, Wang X, Tong L, Zhu X, Zhong N, Bai C, Powell CA, Chen R, Zhou J, et al. (2020) Chinese experts' consensus on the internet of things-aided diagnosis and treatment of coronavirus disease 2019 (COVID-19). Clinical eHealth 3:7-15

64. COVID-19 smartphone testing kit. (2020) https://www.detectachem.com/index.php?p=COVID19. Accessed June 27, 2020

65. United against coronavirus! Stopcorona App. (2020) https://stopcorona.app/. Accessed June 06, 2020

66. Kelion L (2020) Coronavirus: Moscow rolls out patient-tracking app. https://www.bbc.com/news/ technology-52121264. Accessed June 19, 2020

67. 'Selfie app' to keep track of quarantined poles. (2020) https://www.france24.com/en/20200320selfie-app-to-keep-track-of-quarantined-poles. Accessed June 19, 2020

68. Wright $\mathrm{T}$ (2020) Blockchain app used to track COVID-19 cases in Latin America. https:// cointelegraph.com/news/blockchain-app-used-to-track-covid-19-cases-in-latin-america. Accessed June 26, 2020

69. Hui M (2020) Hong kong is using tracker wristbands to geofence people under coronavirus quarantine. https://qz.com/1822215/hong-kong-uses-tracking-wristbands-for-coronavirus-quarantine/. Accessed June 19, 2020

70. Aarogyasetu. (2020)https://www.mygov.in/aarogya-setu-app/. Accessed June 06, 2020

71. TraceTogether, safer together. (2020) https://www.tracetogether.gov.sg/. Accessed June 06, 2020

72. Stub ST (2020) Israeli phone apps aim to track coronavirus, guard privacy. https://www.usnews.com/ news/best-countries/articles/2020-04-20/new-tech-apps-in-israel-aim-to-track-coronavirus-guard-privacy. Accessed June 27, 2020

73. Tokenpost (2020) IoT blockchain platform launches a COVID-19 contact tracing app. https://bit.ly/ 3eS2VGt. Accessed June 27, 2020

74. BeAware Bahrain. (2020) https://bit.ly/2MOQyyt. Accessed June 06, 2020

75. I protect both you and me. (2020) https://erouska.cz/en. Accessed June 10, 2020

76. How WhatsApp can help you stay connected during the coronavirus (COVID-19) pandemic. (2020) https://www.whatsapp.com/coronavirus/. Accessed June 06, 2020

77. Sabeti P (2020) Early detection is key to combating the spread of coronavirus

78. Definitions of symptoms for reportable illnesses. (2020) https://www.cdc.gov/quarantine/air/ reporting-deaths-illness/definitions-symptoms-reportable-illnesses.html. Accessed June 26, 2020

79. Philip R (2020) How IoT sensors can help detect and control contagious diseases. https://www. rfidjournal.com/how-iot-sensors-can-help-detect-and-control-contagious-diseases. Accessed July 01,2020

80. Guk K, Han G, Lim J, Jeong K, Kang T, Lim E-K, Jung J (2019) Evolution of wearable devices with real-time disease monitoring for personalized healthcare. Nanomaterials 9(6):813

81. Haghi M, Thurow K, Stoll R (2017) Wearable devices in medical internet of things: scientific research and commercially available devices. Healthcare Inform Res 23(1):4-15

82. Influenza-like illness levels. (2020) https://bit.ly/3gnpp27. Accessed July 03, 2020

83. McNeil D (2020) Can smart thermometers track the spread of the coronavirus?. The New York Times

84. https://www.kinsahealth.co/. Accessed June 06, 2020

85. Gold J (2020) IoT offers a way to track COVID-19 via connected thermometers. https://bit.ly/ 2XVL1fD. Accessed June 06, 2020

86. Ruktanonchai NW, Ruktanonchai CW, Floyd JR, Tatem AJ (2018) Using Google location history data to quantify fine-scale human mobility. Int J Health Geogr 17(1):28

87. Ghosh S (2020) Police in China, Dubai, and Italy are using these surveillance helmets to scan people for COVID-19 fever as they walk past and it may be our future normal. https://www.businessinsider. 
com/coronavirus-italy-holland-china-temperature-scanning-helmets-2020-51. Accessed June 24, 2020

88. Bright J, Liao R (2020) Chinese startup rokid pitches COVID-19 detection glasses in the us

89. Social distancing wristband - COVID-19 monitoring. (2020) https://shop.kheprainc.com/products/ proximity-alerts-contact-tracing-wristband. Accessed July 10, 2020

90. Proximity Trace. (2020) https://www.triaxtec.com/resource/fact-sheet/proximity-trace/. Accessed June 27, 2020

91. Wearable technology in the time of COVID-19. (2020) https:/www.constructiondive.com/spons/ wearable-technology-in-the-time-of-covid-19/577217/. Accessed June 27, 2020

92. Instant trace. (2020)https://bit.ly/2W9oCKK. Accessed July 10, 2020

93. Dormehl L (2020) Thermal AR glasses give screening for possible coronavirus a high-tech twist. https://www.digitaltrends.com/cool-tech/vuzix-m4000-temperature-checks/. Accessed July 03,2020

94. Horwitz J (2020) Vuzix M400 AR glasses add Onsight Cube thermal scanner for coronavirus

95. Haleem A, Javaid M, Vaishya R, Deshmukh S (2020) Areas of academic research with the impact of COVID-19. The American Journal of Emergency Medicine

96. Chamola V, Hassija V, Gupta V, Guizani M (2020) A comprehensive review of the COVID-19 pandemic and the role of IoT, drones, AI, Blockchain, and $5 \mathrm{G}$ in managing its impact. IEEE Access 8:90225-90265

97. https://draganfly.com/. Accessed July 16, 2020

98. Cozzens T (2020) Pandemic drones to monitor, detect those with COVID-19

99. Pennic F (2020) 'pandemic drone' could detect virus symptoms like COVID-19 in crowds. https://hitconsultant.net/2020/03/27/pandemic-drone-could-detect-virus-symptoms-like-covid-19-incrowds/\#.Xv-Rmed71PY. Accessed July 03, 2020

100. Sharma M (2020) How drones are being used to combat COVID-19. https://www.geospatialworld. net/blogs/how-drones-are-being-used-to-combat-covid-19/. Accessed June 15, 2020

101. Pan C (2020) Spain's military uses DJI agricultural drones to spray disinfectant in fight against COVID-19. https://www.scmp.com/tech/gear/article/3077945/spains-military-uses-dji-agriculturaldrones-spray-disinfectant-fight. Accessed June 15, 2020

102. Yang $\mathbf{J}$ (2020) 3 ways china is using drones to fight coronavirus. https://www.weforum.org/agenda/ 2020/03/three-ways-china-is-using-drones-to-fight-coronavirus/. Accessed June 15, 2020

103. Ackerman E (2020) Zipline wants to bring medical drone delivery to u.s. to fight COVID-19. https:// spectrum.ieee.org/automaton/robotics/drones/zipline-medical-drone-delivery-covid19. Accessed June 15,2020

104. Reagan J (2020) COVID-related drone delivery soars into Canadian first nation. https://dronelife. com/2020/06/10/ddc-drone-covid-drone-delivery/. Accessed July 10, 2020

105. Cyient (2020) Cyient provides drone-based surveillance technology to support Telangana state police in implementing COVID-19 lockdown. https://www.cyient.com/prlisting/corporate/cyientprovides-drone-based-surveillance-technology-to-support-telangana-state-police-in-implementingcovid-19-lockdown. Accessed June 15, 2020

106. Gascueña D (2020) Drones to stop the COVID-19 epidemic. https://www.bbva.com/en/ drones-to-stop-the-covid-19-epidemic/. Accessed June 15, 2020

107. Yang G-Z, Nelson BJ, Murphy RR, Choset H, Christensen H, Collins SH, Dario P, Goldberg K, Ikuta K, Jacobstein N, et al. (2020) Combating COVID-19-the role of robotics in managing public health and infectious diseases

108. https://vayyar.com/. (2020) Accessed July 03, 2020

109. https://www.meditemi.com/en/. (2020) Accessed July 03, 2020

110. Pennic F (2020) Intelligent care robot could detect COVID-19 symptoms in under 10 seconds. https://hitconsultant.net/2020/05/22/intelligent-care-robot-detect-covid-19-symptoms-in-under-10seconds/\#.Xv-naOd71Pb. Accessed July 03, 2020

111. Blunden M (2020) Robots offer a contact-free way of getting swabbed for coronavirus. https:// www.standard.co.uk/tech/robots-offer-new-coronavirus-swab-technique-a4477396.html. Accessed June 24, 2020

112. Ackerman E (2020) Autonomous robots are helping kill coronavirus in hospitals. IEEE Spectrum

113. Manganello K (2020) Xenex lightstrike robot destroys SARS-CoV-2 (coronavirus) in 2 minutes. https://bit.ly/3hpag1B. Accessed June 06, 2020 
114. China buys danish robots to fight coronavirus. (2020) https://www.businesswire.com/news/home/ 20200219005708/en/China-Buys-Danish-Robots-Fight-Coronavirus. Accessed June 06, 2020

115. Yang G, Lv H, Zhang Z, Yang L, Deng J, You S, Du J, Yang H (2020) Keep healthcare workers safe: application of teleoperated robot in isolation ward for COVID-19 prevention and control. Chin J Mech Eng 33(1):1-4

116. Robots help combat COVID-19 in world, and maybe soon in india too. (2020) https://bit.ly/3flejtU. Accessed June 06, 2020

117. PARO therapeutic robot. (2020) http://www.parorobots.com/. Accessed July 10, 2020

118. State V (2020) Visionstate ships first IoT buttons for rapid response to cleaning alerts. https://www. globenewswire.com/news-release/2020/03/23/2004645/0/en/Visionstate-Ships-First-IoT-Buttons-forRapid-Response-to-Cleaning-Alerts.html. Accessed July 03, 2020

119. Choudhary M (2020) How IoT can help fight COVID-19 battle. https://bit.ly/2MNQvD0. Accessed June 06, 2020

120. Julian Watson JB (2020) IoT set to play a growing role in COVID-19 response. https://bit.ly/ 3 fiKqdX, Accessed June 06, 2020

121. D'mello A (2020) First IoT buttons shipped for rapid response to cleaning alerts. https://bit.ly/ 2MSy7Zy. Accessed June 06, 2020

122. IoT alert button finds new uses during coronavirus pandemic. (2020) https://www.med-technews. $\mathrm{com} /$ news/iot-alert-button-finds-new-uses-during-coronavirus-pandemic/. Accessed June 27, 2020

123. Yang T, Gentile M, Shen C-F, Cheng C-M (2020) Combining point-of-care diagnostics and internet of medical things (IoMT) to combat the COVID-19 pandemic

124. Hayes A (2020) Mobiledetect bio BCC19 test kit [fact sheet]. https://www.fda.gov/media/141789/ download

125. Wilder-Smith A, Freedman DO (2020) Isolation, quarantine, social distancing and community containment: pivotal role for old-style public health measures in the novel coronavirus $(2019-\mathrm{nCoV})$ outbreak. J Travel Med 27(2):taaa020

126. Onag G (2020) Smarter IoT apps developed for China's quarantine scenarios. https://futureiot.tech/ smarter-iot-apps-developed-for-chinas-quarantine-scenarios/. Accessed July 04, 2020

127. Vaishya R, Javaid M, Khan IH, Haleem A (2020) Artificial intelligence (AI) applications for COVID19 pandemic. Diabetes \& Metabolic Syndrome: Clinical Research \& Reviews

128. Kupper A, Bareth U, Freese B (2011) Geofencing and background tracking - the next features in lbss. In: Proceedings of the 41th Annual Conference of the Gesellschaft fur Informatik eV

129. Normile D (2020) 'Suppress and lift': Hong Kong and Singapore say they have a coronavirus strategy that works. Science

130. Izaguirre A (2020) Judge OKs ankle monitors for virus scofflaws. https://bit.ly/3eSMZ5D. Accessed July 21,2020

131. Wireless S (2020) COVID-19: How corrections department officials can use electronic monitoring systems to reduce jail overcrowding and keep communities safe. https:/www.sierrawireless.com/ iot-blog/iot-blog/2020/04/electronic-monitoring-systems-reduce-overcrowding/. Accessed July 21, 2020

132. Lancet T (2020) COVID-19: protecting health-care workers. Lancet (London, England) 395(10228):922

133. Elena Romero M (2020) In fight against coronavirus, Ghana uses drones to speed up testing. https:// www.pri.org/stories/2020-04-23/fight-against-coronavirus-ghana-uses-drones-speed-testing. Accessed June 23, 2020

134. Singla P (2020) Drone technology-game changer to fight against COVID-19. UGC CARE J 19(6):78-80

135. O’Meara S (2020) Hospital ward run by robots to spare staff from catching virus. New Sci (1971) 245(3273): 11

136. Avgousti S, Christoforou EG, Panayides AS, Voskarides S, Novales C, Nouaille L, Pattichis CS, Vieyres P (2016) Medical telerobotic systems: current status and future trends. Biomed Eng Online 15(1):96

137. https://www.davincisurgery.com/. Accessed July 09, 2020

138. XDBOT set for COVID-19 cleaning duties in Singapore. (2020) https://www.theengineer.co.uk/ xdbot-set-for-covid-19-cleaning-duties-in-singapore/. Accessed July 10, 2020

139. What is a collaborative robot - COBOT?. (2013) https://www.yaskawa-global.com/product/robotics/ collaborative. Accessed June 25, 2020 
140. Xenex (2018) Martin health system unveils Xenex germ-zapping robot. https://www.xenex.com/ resources/news/martin-health-system-unveils-xenex-germ-zapping-robot/. Accessed June 25, 2020

141. CDC (2020) Mental health and coping during COVID-19. https://www.cdc.gov/coronavirus/ 2019-ncov/daily-life-coping/managing-stress-anxiety.html. Accessed June 16, 2020

142. Baydakova A (2020) Russians troll government COVID-19 app with 1-star ratings, harsh reviews. https://www.coindesk.com/russians-troll-government-covid-19-app-with-1-star-ratings-harsh-reviews. Accessed June 19, 2020

143. Meduza (2020). Surrender everything moscow officials are launching an app to monitor coronavirus patients' compliance with home isolation. it requires access to geolocation, calls, and device settings. https://meduza.io/en/feature/2020/04/01/surrender-everything. Accessed June 19, 2020

144. Geolocation API. (2020) https://mzl.la/37SLTFp

145. Bruce V, Young A (1986) Understanding face recognition. Br J Psychol 77(3):305-327

146. Emerge (2020) Emerge and penta network support public COVID-19 response with civitas. https://medium.com/@EmergeDev/emerge-and-penta-network-support-public-covid-19-responsewith-civitas-515ae2b1cb72. Accessed June 26, 2020

147. India T (2020) Indian government launches Aarogya Setu app to track coronavirus infections. https://www.techradar.com/news/indian-government-launches-aarogya-setu-app-to-crack-coronavirus- infections. Accessed June 27, 2020

148. Online ET (2020) How to use Aarogya Setu app and find out if you have coronavirus symptoms. https://economictimes.indiatimes.com/tech/software/how-to-use-aarogya-setu-app-and-find-out-ifyou-have-covid-19-symptoms/articleshow/75023152.cms. Accessed June 27, 2020

149. Help speed up contact tracing with TraceTogether. (2020) https://www.gov.sg/article/ help-speed-up-contact-tracing-with-tracetogether. Accessed June 19, 2020

150. United against COVID-19. (2020) https://bit.ly/2W9oCKK. Accessed June 06, 2020

151. Fighting against COVID-19 via privacy-first Bluetooth tracing. (2020) https://github.com/covid19cz/ erouska-android. Accessed June 06, 2020

152. Fong MW, Gao H, Wong JY, Xiao J, Shiu EY, Ryu S, Cowling BJ (2020) Nonpharmaceutical measures for pandemic influenza in nonhealthcare settings-social distancing measures. Emerg Infect Dis 26(5):976

153. Zielinski D (2020) Wearables enable distancing, contact tracing at work. https://www.shrm.org/ resourcesandtools/hr-topics/technology/pages/wearables-enable-distancing-contact-tracing-work. aspx. Accessed July 10, 2020

154. Goodchild J (2020) How can drones help in COVID-19 recovery and reopening? https://www. iscnews.com/how-can-drones-help-in-covid-19-recovery-and-reopening/. Accessed July 09, 2020

155. COVID-19 \& the potential rise of a surveillance state through the use of drones. (2020) https:// halanbrickleylaw.com/news/covid-19-rise-of-surveillance-drones/. Accessed June 27, 2020

156. Stankiewicz K (2020) Boston dynamics' dog-like robot Spot is being used on coronavirus social distancing patrol. https://www.cnbc.com/2020/05/15/boston-dynamics-dog-like-robot-spot-used-onsocial-distancing-patrol.html. Accessed June 24, 2020

157. Nalewicki J (2020) Singapore is using a robotic dog to enforce proper social distancing during COVID-19. Smithsonian Magazine

158. Kooser A (2020) Boston dynamics spot robot dog reminds park visitors to maintain distance. https:/www.cnet.com/news/boston-dynamics-spot-robot-dog-reminds-park-visitors-to-maintain-dis tance/. Accessed June 26, 2020

159. Joyia GJ, Liaqat RM, Farooq A, Rehman S (2017) Internet of medical things (IOMT): applications, benefits and future challenges in healthcare domain. J Commun 12(4):240-247

160. Nausheen F, Begum SH (2018) Healthcare IoT: benefits, vulnerabilities and solutions. In: 2018 2nd International Conference on Inventive Systems and Control (ICISC). IEEE, pp 517-522

161. Yu E (2020) Singapore introduces contact tracing app to slow coronavirus spread. https://www.zdnet. com/article/singapore-introduces-contact-tracing-app-to-slow-coronavirus-spread/. Accessed June 19,2020

162. Alladi T, Chamola V, Parizi RM, Choo K-KR (2019) Blockchain applications for industry 4.0 and industrial IoT: A review. IEEE Access 7:176935-176951

163. Yazdinejad A, Parizi RM, Dehghantanha A, Zhang Q, Choo KR (2020) An energy-efficient SDN controller architecture for IoT networks with blockchain-based security. IEEE Trans Serv Comput. $1-1$ 
164. Yazdinejad A, Parizi RM, Dehghantanha A, Choo KR (2019) Blockchain-enabled authentication handover with efficient privacy protection in SDN-based 5g networks. IEEE Transactions on Network Science and Engineering 1-1

165. Srivastava G, Parizi RM, Dehghantanha A (2020) The future of blockchain technology in healthcare internet of things security. In: Blockchain Cybersecurity, Trust and Privacy. Springer, pp 161-184

166. (2020). Global social media overview. (2020) https://datareportal.com/social-media-users. Accessed June 10, 2020

167. Machado RA, de Souza NL, Oliveira RM, Júnior HM, Bonan PRF (2020) Social media and telemedicine for oral diagnosis and counselling in the COVID-19 era. Oral Oncol

168. Agarwal S, Punn NS, Sonbhadra SK, Nagabhushan P, Pandian K, Saxena P (2020) Unleashing the power of disruptive and emerging technologies amid COVID 2019: a detailed review. arXiv:2005.11507

169. Chan B, Paramel R, Williams P (2020) Responding to the COVID-19 pandemic - a collaboration framework for cities and solutions providers. https://strategyofthings.io/wp-content/uploads/2020/ 04/White-Paper-Collaboration-Opportunities-in-Responding-to-the-COVID-19-pandemic.pdf. Accessed July 04, 2020

170. Allam Z, Jones DS (2020) On the coronavirus (COVID-19) outbreak and the smart city network: universal data sharing standards coupled with artificial intelligence (AI) to benefit urban health monitoring and management. In: Healthcare. vol 8, $1 \mathrm{p}$ 46. Multidisciplinary Digital Publishing Institute

171. Gupta M, Abdelsalam M, Mittal S (2020) Enabling and enforcing social distancing measures using smart city and its infrastructures: a COVID-19 use case. arXiv:2004.09246

172. Zhang K, Ni J, Yang K, Liang X, Ren J, Shen XS (2017) Security and privacy in smart city applications: challenges and solutions. IEEE Commun Mag 55(1):122-129

173. Tofel KC (2020) I'm all in with voice in my smart home to reduce coronavirus and other illness potential. https://staceyoniot.com/im-all-in-with-voice-in-my-smart-home-to-reduce-coronavirusand-other-illness-potential/. Accessed June 19, 2020

Publisher's Note Springer Nature remains neutral with regard to jurisdictional claims in published maps and institutional affiliations. 


\section{Affiliations}

Mohammad Nasajpour $^{1}$. Seyedamin Pouriyeh ${ }^{1}$ (D) Reza M. Parizi $^{2}$. Mohsen Dorodchi ${ }^{3}$. Maria Valero ${ }^{1} \cdot$ Hamid R. Arabnia ${ }^{4}$

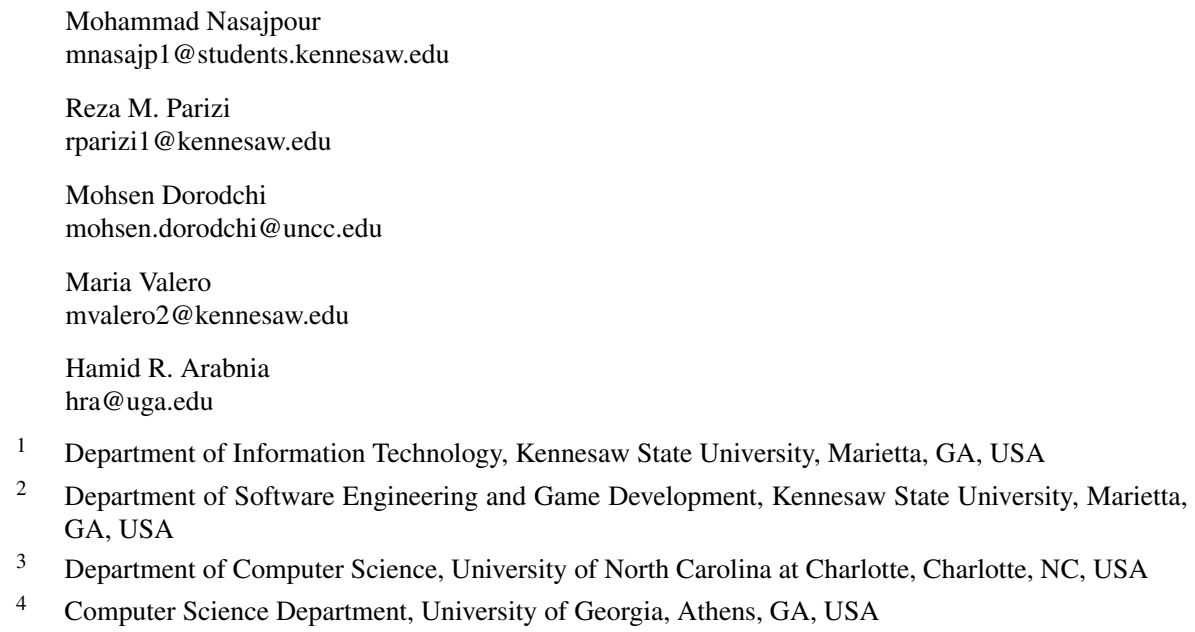

3 Department of Computer Science, University of North Carolina at Charlotte, Charlotte, NC, USA

4 Computer Science Department, University of Georgia, Athens, GA, USA 